\title{
The Bodies of TEI - Investigating Norms and Assumptions in the Design of Embodied Interaction
}

\author{
Katta Spiel \\ katta.spiel@tuwien.ac.at \\ HCI Group, TU Wien \\ Vienna, Austria
}

\begin{abstract}
In the few decades since the first mainframe computers, computing technologies have grown smaller, and more pervasive, moving onto and even inside human bodies. Even as those bodies have received increased attention by scholars, designers, and technologists, the bodily expectations and understandings articulated by these technological artefacts have not been a focus of inquiry in the field. I conducted a feminist content analysis on select papers in the proceeding of the ACM International Conference on Tangible, Embedded and Embodied Interaction (TEI) since its inception in 2007. My analysis illustrates how artefacts are implicitly oriented on unmarked bodily norms, while technologies designed for nonnormative bodies treat those as deviant and in need of correction. Subsequently, I derive a range of provocations focused on material bodies in embodied interaction which offer a point of reflection and identify potentials for future work in the field.
\end{abstract}

\section{CCS CONCEPTS}

- Human-centered computing $\rightarrow \mathrm{HCI}$ theory, concepts and models; Interaction design theory, concepts and paradigms; - Social and professional topics $\rightarrow$ User characteristics.

\section{KEYWORDS}

Embodiment; Bodies; Representation; Somaesthetics; Feminist Content Analysis; Norms; Embodied Computing; Design

ACM Reference Format:

Katta Spiel. 2021. The Bodies of TEI - Investigating Norms and Assumptions in the Design of Embodied Interaction. In Fifteenth International Conference on Tangible, Embedded, and Embodied Interaction (TEI '21), February 1417, 2021, Salzburg, Austria. ACM, New York, NY, USA, 19 pages. https: //doi.org/10.1145/3430524.3440651

\section{INTRODUCTION}

(Predominantly human) bodies stand, implicitly and explicitly, at the centre of the somatic turn in Human-Computer Interaction (HCI) [73]. Innovations occur in the area of wearables (e.g., [100], on-body tattoos (e.g., [130]) or somaesthetic mats (e.g., [49]) and directly engage bodies in technological interaction - even beyond the dedicated conference on Tangible, Embedded and Embodied Interaction (TEI). 4.0 License.

TEI '21, February 14-17, 2021, Salzburg, Austria 2021. ACM ISBN 978-1-4503-8213-7/21/02.

https://doi.org/10.1145/3430524.3440651
However, bodies and how we design for them are products of social norms $[67,74]$. While there are attempts to deconstruct the gendered view of a default male body and its implications for $\mathrm{HCI}$ (i.e., [3]), singularly focusing on, e.g., cis $^{1}$ women in $\mathrm{HCI}$ reproduces similarly restrictive notions around otherwise marginalised bodies [61]. Critiques stemming from Science and Technology Studies (STS) have been successful in drawing out the underlying ideologies on technologies related to bodies, such as the assumption of individualised responsibility [75] - to the detriment of anyone who might not be able to perform to implicit bodily standards. This mainly affects, for example, disabled, fat, indigenous, and/or black people, those who have a 'minority body' [12] within specific cultural and technological settings. Especially in the context of fitness trackers, the people using them appear to be white, able-bodied, mentally stable, reasonably young, already fit and slim as a default [118]. Even if we assume that these categories cover the majority of people engaging with fitness trackers, even though they most likely do not, only designing for these creates exclusions that are ultimately inconsistent with the proclaimed motivational and health-related benefits of fitness trackers. ${ }^{2}$

Somatic technologies, those that are placed or focused on or within human bodies, and the ideologies they embody need to be actively articulated and reflected upon by designers of embodied interactions. The critical engagement with current literature and existing artefacts offers an opportunity to reflect on the consequences of ingrained assumptions built into technologies [71] and allows designers to imagine and create meaningful alternatives productively. To develop such a practice, we require a broader analysis of selected texts and artefacts within the field, one that this work attempts to contribute to by attending to a corpus of 45 papers published in the 14 years since the inception of the TEI conference. My focus lies specifically on identifying the norms that shape the design and development of embodied computing technologies. As the TEI community grapples with the implications of the somatic turn, I deem it timely to critically examine existing implicit biases so that we may move forward with creating innovative designs and technologies acknowledging and appreciating the plurality of human bodies instead of assuming a specific embodiment.

In the remainder of this paper, I first provide my theoretical and general background on three different ways HCI in general and the TEI community in particular talk about embodiment: as a way of cognition, a way of interacting, and a way of designing; which I then augment by laying out existing critical perspectives on bodies

\footnotetext{
${ }^{1}$ The prefix cis refers to people who's gender identity aligns with the gender they were assigned at birth [7]

${ }^{2}$ I would be remiss not to mention here the important work by, e.g., Carrington et al. researching the feasibility for fitness trackers in the context of wheelchair sports [18].
} 
in interaction design. After detailing my methodological approach, I provide a description of the corpus and illustrate tendencies I found in and across specific instances. Finally, I discuss the material consequences of normativising tendencies in the analysed works leading to a set of provocations for designers and researchers of embodied interactions. The critical perspective I offer is intended to stimulate a larger discussion within the field to reflect on its implicit and explicit norms.

\section{BACKGROUND}

Where human bodies were initially understood as disruptive elements in computing,they were increasingly thought of as 'human factors' in interaction, further cogs to consider. With devices and computing power becoming smaller and increasingly mobile, moving on and even into human bodies, computing generally and Human-Computer Interaction specifically grapple with the cognitive, interactive, designerly, and critical implications thereof.

\subsection{Embodied Cognitions}

The advent of tangibles, embedded and embodied computing brought along sustained excitement about the potentials of overcoming the digital/physical divide $[55,56]$. One of the core advantages were identified in augmenting embodied aspects of cognition [62] and embodied sense-making as ways of thinking through body-world couplings. The prevalent notion of embodied computing rarely accounts for the pluralities and differences in human embodiments and their subsequent implications for human cognition. Exceptions lie in works on the range of (micro)movements performed by different bodies [16] and the theoretical tie-ins with, e.g., pragmatist philosophies of embodiment [17]. Hence, even though the notion of embodied cognition aims at dissolving the Cartesian mind/body split [126], currently dominant understandings could be expanded and further specified by drawing on more integrated bodymind concepts from Disability Studies (e.g., [20, 110]).

While in my analysis, I do not focus on cognition so much as on representation and conceptualisation of bodies in embodied computing presented at TEI, I need to acknowledge the prevalence of these concepts. Specifically, as there exists a direct link between embodied cognition with its interactive notions of pragmatic (i.e., goal-oriented) and epistemic (i.e., explorative) actions [63] and the prominent phenomenologically driven conceptualisation of "where the action is" [28].

\subsection{Embodied Interactions}

Phenomenology, a philosophical tradition of thought aiming at an understanding of embodied and situated experiences, offered a fruitful theoretical backing present in many of HCI's notions of how bodies and technologies might interact with each other. Since the initial introduction of phenomenological embodiment theories conceptualising embodied interaction as situated, specific, felt but also, to some extent, mundane [28], other accounts have further developed this notion. Specifically in the context of games and play, recent work drew on German distinctions between having and being a body to understand the qualitative differences in different forms of interactive engagements [88] or developed the concept of surrogate bodies that are formed through the intersubjective interaction between human bodies and games [117]. Other approaches have presented "Kinesthetic Interaction as a unifying concept for describing the body in motion as a foundation for designing interactive systems" [33].

Current debates within HCI and TEI communities around inbodied interaction [5, 6] and the potentials of 'Human-Computer Integration' [87], though, are conspicuously under-theorised - and do not lend themselves easily to the phenomenologically driven frames noted above. In this context, recent work encourages HCI research to draw on a more diverse set of humanistic theories [9]. These include critical investigations, which have the potential to not just inform our conceptual understanding of how human bodies might interact with technologies but further advance the reflective components of embodied design methods - specifically in attending to differences in embodiments.

\subsection{Somaesthetic Designs}

Early suggestions on how to attend to bodies in interaction design draw on notions of embodied cognition, embodied ways of 'doing things', making bodies (and technologies) visible, or assessing material risks in combination with "thick practice", i.e. a reflective, considerate and richly constructed design endeavours [65]. While, to some extent, such work has been motivated by providing a more actionable interpretation of phenomenological approaches, Svanæs tied in the implications of phenomenological philosophy for design practice more directly, specifically by designing with and for embodied perception (i.e., the way the entire body is involved in making sense of an environment) as well kinesthetic creativity (i.e., the way bodily affect is involved in the design of interactive technologies) [121]. In a similar vein, Höök reminds us to acknowledge and attend to our specific, situated and individual embodiment in design processes [48] and presented a notion of "somasthaetic design" aiming at a synthesised approach to designing simultaneously with and for human bodies [50].

Related works have developed approaches to particularly use bodies in motion as a resource for design. Among those are the "bodystorming" method inviting designers to concretely act out interactive scenarios of technologies they design [113], systematic and interactive processes of analysing and investigating movement in design and deliberately "making strange" [72], as well as playful approaches like "embodied sketching" [77] and methods that specifically attend to the unique movement patterns children might exhibit [111].

This comparatively small selection of works discussing how bodies might be theorised in making sense of, interacting with or designing for embodied computing broadly illustrates the rich ways in which HCI research has grappled with this group of technologies. While these works present an important background for my investigations to keep in mind, my contribution here is intended to offer a critical perspective on how the design of embodied artefacts materialises implicit norms and assumptions. For this, I turn to the development of critical analyses of technologies as they become more and more prevalent in the field. 


\subsection{Critical Perspectives on Bodies in Interaction Design}

With the formal introduction of critical feminist theories into $\mathrm{HCI}$ [10], feminist scholars have brought in the lived body as a reflective lens on technological design [106]. While my work here does not attend to the lived experiences people might have with the technologies I analyse here, I am still guided by an attempt to "understand an individual's unique viewpoint in the context of a particular history and culture, rather than additively trying to combine differing labels of gender or race" [106, p.399]. This means, concretely, that I attend to experiential differences in lived embodiments and keep in mind different marginalisations that act in specific ways on specific bodies.

Prior work has similarly aimed at pointing out normative practices in technology design and engineering more generally [96]. Within HCI, researchers have pointed to several axes of oppression in technology design and researchers. Along gender, work has discussed how most health related technology research addresses almost exclusively white cis-male bodies [3] and how gender is reductively encoded and materialised along binary, immutable concepts [119]. Further critique has addressed how disabled bodies are systematically kept out of assistive technology research [76] instead of being attributed unique expertise [105] or just being acknowledged as colleagues [134]. These experiences are echoed by BIPOC $^{3}$ scholars regarding the systemic oppression of their research as well as their person, urging the field to adopt perspectives and epistemologies informed by Critical Race Theory [101].

Hence, critical perspectives on bodies involved in and on embodied computing and the specific norms informing the field in designing and developing such technologies can offer a point for reflection. Designers might not just use such work to make implicit norms explicit and negotiable, but also move beyond their individual embodiment in acknowledging difference. Further, critical perspectives provide a starting point for attending to the material consequences of technology design beyond phenomenological assessments and sensitise researchers as well as designers to the richness of knowledge and understanding stemming from the range of experiences made by diverse bodyminds.

\section{METHOD}

I situate this work within feminist methodology, which has been adapted to the specificity of HCI research [11]. Specifically, I follow principles of Feminist Critical Discourse Analysis (FCDA) [68], which are illustrated in detail in Table 1. Fundamental to this endeavour is an understanding of power as a combination of modern concepts of dominance coexisting with traditional hegemonic power relations. As Lazar states, "[f]or FCDA, the task then is to examine how power and dominance are discursively produced, resisted, and counter-resisted in a variety of ways through textual representations of gendered social practices, and through interactional strategies of talk." [68, p.189].

Quantitative and qualitative content analysis appears in various flavours in HCI literature, though largely without providing external references to a specific method or approach. For example,

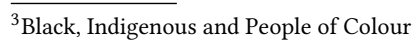

Himmelsbach et al., conducted a quantitative content analysis to understand if and how the HCI literature articulates care regarding diversity issues[45]; Keyes reviewed works in the area of automated gender recognition through (quantitative) content analysis, but similarly does not provide a concrete methodological reference [60]; and Andalibi et al. analysed Instagram content tagged with \#Depression to understand social support in this space better [4]. However, none of these works contain methodological references alluding to the epistemological commitments involved beyond other works employing similar approaches. However, across these publications, content analysis constitutes a critical engagement with a large corpus of media, including textual and non-textual material.

To guide my analysis more structurally, my work follows the implementation of Feminist Content Analysis (FCA) $[69,70]$ consisting of six distinct steps, each of which requiring readjustment according to prior choices.

3.1 Transformation of the topic into a research purpose statement and research questions as well as expectations to set the outline of the research design.

3.2 Process of assembling source material that is suitable to the topic and its questions while remaining feasible to manage as a corpus for inquiry.

3.3 Initial immersion with the corpus material to refine its scope and get an initial feeling for its contents.

3.4 Closely reading the corpus material, writing memos and identifying inductive codes as well as appropriate theoretical lenses supporting deductive codes.

3.5 Construction of a dimensional narrative from initial themes while reflecting on researchers' positionality within the analysis ${ }^{4}$.

4 Establishing relevant findings and appropriate critical insights in discussing the source material largely in the process of writing a given manuscript.

Within social sciences, content analysis has been deemed useful to support exploratory as well as explanatory research endeavours [94] such as mine. Validity and authenticity are achieved by transparently outlining methods, standpoint [44] and consistency in reporting. The goal is to induce persuasiveness, coherence and stringency into an argument and to articulate a situated reading and analysis from a relevant position.

\subsection{Research Purpose Statement}

With this research, my intent was to identify how publications on embodied computing conceptualise bodies. Specifically, I am interested in critically examining this space against the theoretical backdrop of "corporeal theories". My concrete questions are: Which norms, if any, guide embodied computing research in HCI? How are different bodyminds conceptualised in artefacts as well as publications? Which bodies are attended to, which ones are conspicuously absent? Which assumptions guide researchers in the design and description of embodied computing? Influenced by my prior engagement with the field, I expected to find a fairly constrained set of represented bodies, generally normativising tendencies on expected embodiments and an implicitly imagined body ideal. My

${ }^{4}$ Please note that the first part is folded into results within this manuscript and the referenced section solely reflects on my positionality. 


\begin{tabular}{llr}
\hline Principle & Practice & Section \\
\hline Acknowledging materiality & $\begin{array}{l}\text { Explicitly attending to material consequences of dominant dis- } \\
\text { courses in the source material }\end{array}$ & 5.1 .2 \\
Aiming at transformation & Engaging in feminist political imagination & 5.2 \\
Research as analytical activism & Attending to personal implications and standpoints & 1 \\
Marginalisation as ideological & Understanding bodymind work and design as influenced by & 2,5 \\
structure and practice & powerful social constructs and continuous negotiations & 5.1 .1 \\
Complex concepts of power & (De)constructing the bodily concept in the source material & 6 \\
Critical Reflexivity & Delineating the limitations of scope and positionality inherent & \\
& in the work &
\end{tabular}

Table 1: Methodological principles of Feminist Critical Discourse Analysis (with light adaptations for the current context), along with their implications for conducting research, analysing source material and presenting work as well as relevant sections addressing a given principle

interest here lies in identifying not just past trends and critically investigating a status quo but also opportunities for future research and suitable guiding principles.

\subsection{Corpus Construction}

To assemble my corpus for analysis, I identified the entirety of the TEI (International Conference on Tangible, Embedded (and Embod$\mathrm{ied}^{5}$ ) Interaction) conference proceedings since 2007 as a suitable starting point for my investigation. While any interaction with technology can be thought of as implicitly embodied [28, 117], I understand embodied computing as those technologies which "promise to reconfigure the relationship between bodies and their environment, enabling new kinds of physiological interfacing, embodiment, and productivity" [102]. Embodied interactions have garnered quite some interest in recent years and in constraining the venue to papers published at TEI, I could not only pragmatically restrict the size to a manageable corpus but also cut across 14 years of research within a developing and vibrant community to potentially identify changes and trends in this area.

\begin{tabular}{|c|c|c|c|c|c|c|c|c|c|c|c|}
\hline$n=556$ & & & & & & & & & & & Initial sample \\
\hline$n=152$ & & & & & & & & & & & Abstract inspection \\
\hline$n=102$ & - & & & & - & - & & & - & - & Length Filter \\
\hline
\end{tabular}

Figure 1: Schema for the corpus construction procedure.

As a first step, I read all titles and abstracts of all papers in the TEI proceedings since 2007 for a total of 556 publications including full papers, short papers (until and including 2015) and pictorials (for 2020). In reading the titles of abstracts of these 556 publications, I paid close attention to if and how the work mentions bodies ${ }^{5}$ since 2010

\begin{tabular}{lccccl}
\hline Year & Initial & Abstract & Length & Content & Papers \\
\hline 2007 & 50 & 13 & 6 & 3 & {$[66,86,112]$} \\
2008 & 46 & 7 & 4 & 0 & \\
2009 & 71 & 12 & 6 & 2 & {$[47,132]$} \\
2010 & 25 & 7 & 5 & 2 & {$[13,46]$} \\
2011 & 58 & 21 & 12 & 3 & {$[36,80,84]$} \\
2012 & 48 & 14 & 6 & 2 & {$[8,43]$} \\
2013 & 32 & 6 & 6 & 0 & \\
2014 & 46 & 19 & 11 & 7 & {$[30,31,89,93,103,126,128]$} \\
2015 & 34 & 6 & 5 & 2 & {$[19,53]$} \\
2016 & 33 & 9 & 9 & 5 & {$[35,58,115,120,127]$} \\
2017 & 25 & 6 & 6 & 4 & {$[99,104,108,125]$} \\
2018 & 24 & 8 & 8 & 5 & {$[27,29,42,64,95]$} \\
2019 & 20 & 5 & 5 & 1 & {$[122]$} \\
2020 & 44 & 19 & 19 & 9 & {$[32,54,57,85,90-92,98,124]$} \\
\hline total & 556 & 152 & 102 & 45 & \\
\hline
\end{tabular}

Table 2: Distribution of publication funnelling across conference proceedings and final papers per year. The individual counts indicate representation of all papers under review initially, how many remained after inspecting abstracts and assessing paper length (for the years up to and including 2015) and reviewing the content of the papers.

and/or embodiment, presents spatial or full-body related technologies, refers to somatics or body work (including health, fitness and therapy devices). I excluded location-based technologies, any technological setup that was purely touch based (i.e., not related to the body beyond tangibility), works related to data physicalisation and architecturally embedded projects such as furniture or ambient displays. Rather, my focus was on full body interaction, movement and wearables as I deemed those to be more likely to offer fully embodied experiences and address different embodiments. This left me with a total of 152 papers (see also, Figure 1). Table 2 illustrates how papers were distributed across the yearly proceeding for each stage of corpus construction. In a next step, I excluded studios, short 
papers (less than six pages) and other ephemeral, non-archival publications as they cannot be assumed to have a deep engagement with bodily concepts in their works due to space constraints and purpose of these manuscripts.

\subsection{Inititial Immersion}

As part of my initial immersion with the corpus, I removed an additional 57 papers from the sample, leaving me with 45 papers for the in-depth analysis (as shown in Table 2). At this stage, papers were removed either due to a limited involvement bodies by only focusing on hands or arms (e.g., smart watches) ${ }^{6}$ or technology relying largely on (multi-touch) displays (e.g., ReacTable, mobile phone applications). This decision was informed by my interest in fully embodied interaction that conceptually involves entire bodies more explicitly as to not create an artificial split of either how technology senses human bodies (e.g., through inference of arm related movements) or the how these bodies engage with technology (e.g., only with distinct body parts).

\subsection{Coding}

The corpus was deductively coded along implicit assumptions and bodily conceptualisations within the research, artefacts and design processes. I additionally distinguished the works according to contribution type, representation and theoretical background to allude to the implicit normsetting within the field. I understand a norm here as the inherent assumptions made about bodily characteristics of the people envisioned to interact with embodied computing.

\subsection{Positionality}

The author of this work has continually lived, worked, learned and researched in Central Europe. They are white, nonbinary and identify as disabled and neurodivergent. In their scholarly background, they combine humanistic, technical and design expertise with a strong commitment to situated epistemologies [40,52] and transformative research oriented on social justice.

\section{RESULTS}

After a more general description of the corpus characteristics, I structured the presentation of my findings along the four contribution types, I identified (loosely following the suggestion by [131]): publications exploring potential materials, delineating their design processes, presenting artefacts to specific technologies, as well as those discussing theoretical approaches. I chose this structure to allow readers to more easily identify how norms might impact specific areas of embodied computing.

\subsection{Corpus Description}

The final papers in my corpus are detailed in Table 2. Their distribution across publication years is further illustrated in Figure 2, indicating overall increasing publication activity along waves. While other venues also publish on embodied computing, the interest is, ultimately, sustained and saw a recent resurgence in the 2020

\footnotetext{
${ }^{6}$ It could be argued that any kind of engagement with technology is always fully embodied (akin to [117]). However, I deliberately excluded hand-only technology to not bias my corpus towards hands-focused bodily involvement and to have sufficient space for analysing the remaining papers.
}

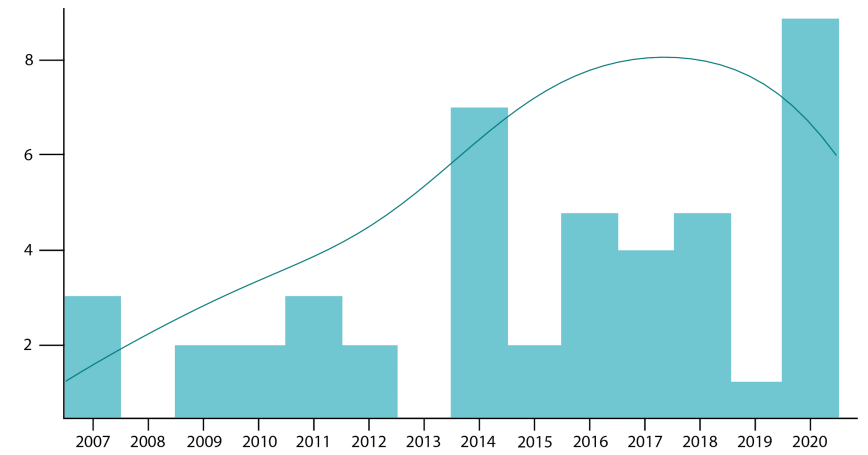

Figure 2: Histogram of paper instances in the corpus along year with a tendency line illustrating waves of interest in embodied computing at TEI. Note that the tendency line points down even though 2020 saw a reinvigorated increase in interest.

proceedings. It should further be noted that even in years where there is no full paper reference instance in my corpus, short papers, demonstration and workshops were still actively concerned with embodied computing.

Table 3 provides an overview of how the papers in the corpus are distributed along contribution types. As a single paper can make more than one contribution, the counts and percentages do not add up neatly to 45 or $100 \%$ respectively. Regardless, the table shows a prominent focus on works concerning technology and, somewhat less, design with theoretical and material contributions being less represented. Given that TEI is a conference organised within the Association for Computing Machinery (ACM) such a focus is somewhat unsurprising. However, the low degree of theory oriented papers, only three of which being unique to the category indicates a missed opportunity for more detailed (critical) reflection and underlines the applied character of the field.

In the remainder of this section, I will step through each contribution type by providing a summary of the papers, attending to the bodies represented (if any) before turning toward the specific assumptions and their normative implications. In my critique, I do not mean to single out individual papers or scholars; no individual paper or group can address all axes of marginalisations by themselves. However, drawing these instances out and putting them in the broader context within the corpus, provides readers with concrete examples for sometimes abstract concepts.

\subsection{Bodies as Material}

The five papers offering a material contribution type (see also, Table 7) have all been published in the last five years, making this a fairly recent trend in embodied computing at TEI. All of them are roughly concerned with material resources, albeit in different notions. One invites the field to understand thermal stimuli as a designerly component [58], two provide tool-kits supporting different aspects of designing for embodied computing [57, 115], one develops building blocks for flexible technological structures with the potential to be included in fabrics [29] and one discusses the potentials of human bodies (specifically hair) as material [27]. 


\begin{tabular}{llll}
\hline Contribution & & Count & Papers \\
\hline Material & 4.2 & $5 \mid 11 \%$ & {$[27,29,57,58,115]$} \\
Design & 4.3 & $18 \mid 40 \%$ & {$[8,13,32,53,54,57,85,86,92,95,103,104,108,115,122,124,125,127]$} \\
Technology & 4.4 & $28 \mid 62 \%$ & {$[19,30-32,35,36,42,43,46,47,54,64,80,84,89-92,98,99,103,104,112,120$,} \\
& & & $122,124,128,132]$ \\
Theory & 4.5 & $11 \mid 24 \%$ & {$[31,53,66,86,90,91,93,98,99,125,126]$} \\
\hline
\end{tabular}

Table 3: Papers in the corpus along contribution types. Note that a single paper can contain more than one contribution.
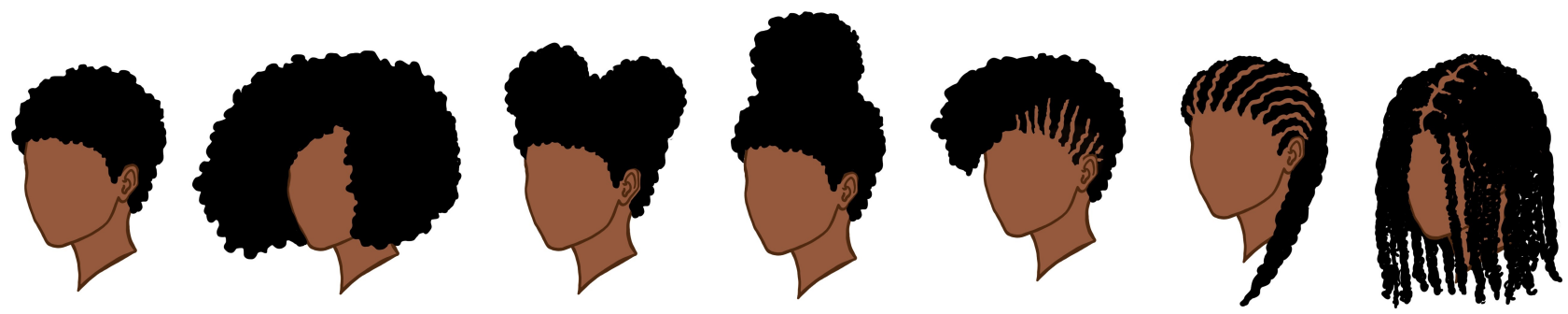

Figure 3: Illustration of different Afro hairstyles as an inspiration to think about human hair beyond white people's hair. Illustration and $\odot$ by Dr Makayla Lewis. These images are not royalty free images and may not be used for commercial or private use. Any such use of these images is strictly prohibited. Specifically, these images may not be copied, manipulated, be reproduced by any other means nor sold without prior written consent by the author, Dr Makayla Lewis.

All papers share a visual focus on materials instead of bodies. Even if on a language level, bodies are present, in figures, they are largely reduced to partial aspects (predominantly hands) or entirely absent. In that, two papers attend to bodymind differences in perception and sensemaking [58] or physical characteristics [57]. All visible bodies or body parts are light-skinned or white and appear youthful. This could be seen as 'merely' an issue of representation, though it becomes striking in the context of HäirIO [27], where the authors exclusively discuss the properties of nonblack hair while referring to it as 'human hair'. They do so without reflecting on the oppressive politics around black hair [83] also as an intersectional aspect particularly affecting black women [22] and even contributing to it by defaulting to white people's hair as 'human hair', implicitly rendering black hair as less-than-human. Beyond this equity related issue, black hairstyles might productively challenge the initial design for which Dr Makayla Lewis helpfully provided a visual starting point in Figure 3.

As the papers are somewhat removed from physical bodies due to their pre-designerly focus, their assumptions are more based on the types of technologies they may afford. For example, [58] envisions reflective technologies oriented on body awareness whereas [115] assumes that supporting designers' embodied sense-making is largely done through touching with hands even though most of the material in the toolkit could feasibly be used in different ways. Another paper, however, illustrates how material-technological exploration sometimes assumes bodies to be a separate issue to attend to, given how "[o]ne of the main limitations of ShapeTex is the large current for heating which can cause three problems: safety, energy efficiency and heat" $\left[29\right.$, p.173]. ${ }^{7}$

Material contributions to embodied computing at TEI are generally oriented towards experiences and exploration of options and opportunities for designs. Norm-setting is more implicit, though in cases where physical differences are explicitly reflected (e.g., [57]), toolkits and building blocks can materialize an expectation of bodily diversity, whereas others privilege technological perspectives to the point where safety considerations for any body appear to become secondary [29]. Particularly, when elements of human bodies are understood as a material resource, researchers seeking to make contributions to this space need to actively consider different experiences of oppression and existing norms around bodies not just within their immediate lived experiences.

\subsection{Bodies in Design}

In total, 18 papers make contributions to the design processes of embodied computing within my corpus (see also, Table 8). Specifically, three papers explore potential avenues for design within concrete constraints, six provide guidance for design through toolkits, methods or offering 'strong concepts' [51] to think with. The remaining nine papers present a range of case studies illustrating contextual design processes together with the ramifications of the resulting technologies. The details of which paper makes which contribution are elaborated on in Table 4.

${ }^{7}$ This work also points to heat not only having aesthetic qualities when encountered by human bodies. 


\begin{tabular}{lll}
\hline Contribution & Count & Papers \\
\hline Exploration & $3 \mid 17 \%$ & {$[13,108,127]$} \\
Guidance & $6 \mid 33 \%$ & {$[53,57,92,115,124,125]$} \\
Case Studies & $9 \mid 50 \%$ & {$[8,32,54,85,86,95,103,104,122]$} \\
\hline
\end{tabular}

Table 4: Specific contribution types within papers making a design contribution. Percentages are derived from the $n=18$ of design-related papers.

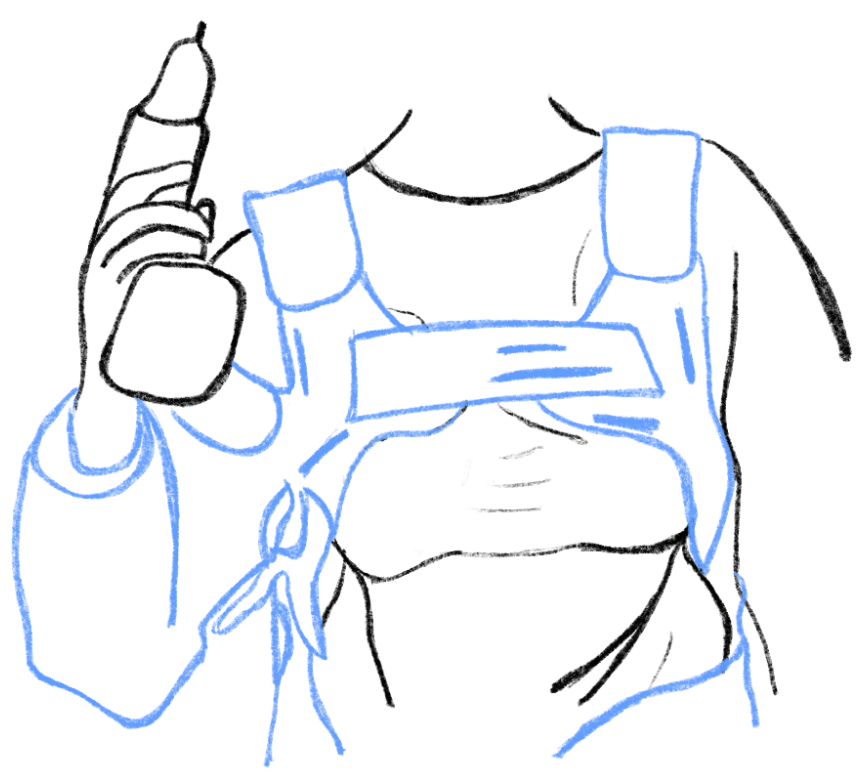

Figure 4: Uncomfortable soft robotics if wearers with breasts. Image drawn from photographs in [32].

The few instances in which bodies are referred to in plurality are 1) case studies detailing design processes for groups of human bodies either in dance [54] or as part of an orchestra [104] and 2) explorations on interactive performance [108] with singular and multiple bodies. Figures in the reviewed works prioritise the depiction of white bodies throughout. There is one exception by authors from Asian institutions [95], though their work presents an interface for embodied level design of augmented reality play, which systematically (as in: on a system level as well as an instance of systemic thinking in the field) implements a notion of the ideal body as the body of the designer(s). However, this is also limited to classically flat-chested cis-male bodies, given that a case study in wearable soft robotics supports creates a prototype entirely oriented on flat chested mannequins and illustrations; which results in photographs of large-chested participants uncomfortably squeezing into their bodies [32] (see also, the sketch in Figure 4). In a particular instance, the authors work with one participant in developing a situated approach to posture correction, albeit never address the issue of that participant also being white, informing fundamentals of the design such as taking black-coloured markers on white skin as a starting point guiding the entire process [85] (see also, Figure 5).

Designerly contributions make specific assumptions about bodies along two conceptualisations. For one, they designate deviant bodies as potential sites for intervention and reflection, bodies that need to be "put in shape" and 'corrected' (e.g., [8, 85, 124]). These are in stark contrast to bodies being admired for movements appreciated as feats (e.g., [103]) or artistic expression (e.g., [86]). If not explicitly attended to deviance, designerly assumptions tend to default to implicit norms largely by what remains unaddressed. For example, in delineating the potential of embodied computing for playful eating experiences [92], the authors presume that eating and food is inherently related to joy, implicitly disregarding the high (and increasing) prevalence of eating disorders [34] as well as the problems faced by people in poverty regarding food security. (Temporally constrained) limitations on food comprise positively connotated experiences only for those who did not have to face these limitations outside of their own volition. In cases where bodily difference is accounted for (e.g., [86, 108]), these difference appear to operate within a conceptually tied frame where movement and dance does not account for people using wheelchairs or crutches.

Designerly norms in embodied computing position themselves critically towards the visual and, to a lesser extent, auditory priority in aesthetics. They bring in touch, movement, and the entire body into aesthetic appreciation. However, this aesthetic focus appears to be less enunciated in contexts where bodies function as a site for intervention. Functionality comprises the main interest here, with work on interactive jewellery [127] disrupting this norm from within. Recent work has also delineated how functionality and aesthetics can be attended to on an equal level throughout the entirety of design processes [85]. Considering all this, designers currently appear to not be trained to reflect on issues such as taking a white body as instance for human bodies (even without ever naming said reference body as white [85]) or using restraint or limitations as experience [92], effectively implying that these are not already present.

\subsection{Bodies with Technologies}

Within the corpus, I identified 28 papers making one or more concrete technical contributions (see also, Table 11). In the spirit of looking "where the action is" [28], I grouped technologies according to which actions they afforded: Five papers present wearables, eight delineate the potentials of play, seven are located within contexts of making music and art (including artful explorations of maths subjects [84]), and another eight papers focus on experiences of feeling and reflecting on those. The specific groupings are further detailed in Table 5.

The representation of bodies in technology oriented papers is often as a backdrop; some papers focus so much on the technological and/or theoretical discussions, they represent not a single living/lived body at all [98]. In other papers, the body might be linguistically absent, though ever present (and implicitly gendered in binary normative ways) visually [64]. As I have already mentioned the overt focus on white and light-skinned bodies, it appears almost cynical, that, within the corpus a green body (represented through a fictional avatar) is more easily found [80] than real-world 

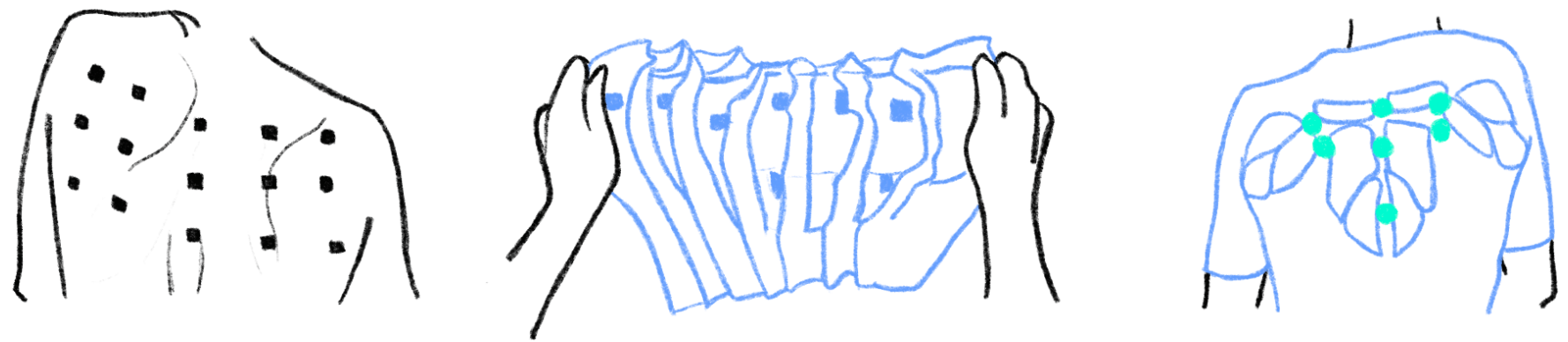

Figure 5: Tracing of the design process detailed in [85]. The highlights in the final picture are present in the original work. Drawing by the author as traced from images of the source publication.

\begin{tabular}{lll}
\hline Group & Count & Papers \\
\hline Wearing & $5 \mid 18 \%$ & {$[32,64,98,99,122]$} \\
Playing & $8 \mid 29 \%$ & {$[19,36,80,89-92,103]$} \\
Making Music \& Art & $7 \mid 25 \%$ & {$[30,46,47,54,84,104,132]$} \\
Feeling \& Reflecting & $8 \mid 29 \%$ & {$[31,35,42,43,112,120,124,128]$} \\
\hline
\end{tabular}

Table 5: Action-groupings within papers making a technology contribution. Percentages are derived from the $n=28$ of technology-related papers.

black bodies. Virtual body representations are strongly normative through the options they offer; none of which include visible disability markers, or even just a fat ${ }^{8}$ body (see, for an example where a body is directly virtually slimmed, [30]).

Technological contributions materialise and (literally) encode further assumptions. While authors mention the importance of attending to the aesthetic qualities of fabrics, including how they feel [99], they do not actively engage with the notion that different people might experience certain fabrics (or wearable constructions more generally [64]) differently. Attending to calibration and adaptation is only ever discussed in the context of non-normative bodyminds [36] without specifying what the concrete normative expectations would be. Another assumption can be summarised as "[a]ll participants were male" [46, p.22]. While this is not the case for all papers (and even presumably decidedly not for others, e.g., [64]), conventionally cis-male coded culture as show of force [89], skill [103] or expertise [46] further insinuate the assumption of a (white) cis-male body as expected target group. Authors similarly rarely specify the required skills relevant to engage with a specific technology [47], even if increased diversity of bodyminds engaging with a technology might lead to meaningful insights [84]. Additionally, some papers assume technologies as superior to 'the lived body' in that they might guide bodies into developing appropriate skills [132], disregarding potentially ambiguous and individually differing body signals in favour of providing numerical representations as communication starters [128] or translating bodily signals more generally [35].

\footnotetext{
${ }^{8}$ I use the word fat as a neutral descriptor. For more on this, please consider [109].
}

Hence, norms in technologies are expressed as to who they fit, directly through avatars and the skills they expect from the people interacting with them. To that effect, black, disabled, fat and genderbinary-non-conforming bodies are largely absent from the equation if not specifically in the focus as deviating from an unspecified norm - a norm that also shifts due to, for example, gendered expectations.

\subsection{Bodies in Theory}

A total of eleven papers explicitly provide a theory oriented contribution (see also, Table 12). In this area, I group instances along their theoretical background as shown in Table 6. The two papers not referencing a specific theory make ontological distinctions between categories of different technologies. Two further paper draw on aesthetics, movement and/or dance theory. The remaining seven draw on phenomenological theories, specifically drawing predominantly on versions presented by Heidegger, Dewey, Merleau-Ponty, and Husserl. ${ }^{9}$ However, in my analysis here, I will not further attend to the theoretical specifics and instead focus on representations of and assumptions on bodies akin to the contribution types analysed above.

\begin{tabular}{lll}
\hline Background & Count & Papers \\
\hline None Specified & $2 \mid 18 \%$ & {$[90,98]$} \\
Aesthetics \& Dance & $2 \mid 18 \%$ & {$[31,86]$} \\
Phenomenology & $7 \mid 64 \%$ & {$[53,66,91,93,99,125,126]$} \\
\hline
\end{tabular}

Table 6: Theoretical background in papers with a theoretical contribution. Percentages derived from $n=11$ of theoryrelated papers.

Most strikingly, bodies are talked about in the abstract, a strategy that strips away attention to details and differences. Subsequently, it is relevant to acknowledge absences. For example, if walking is established as a mode of supporting creativity [31], this has implications for people moving by using wheelchairs, crutches, scooters or other aids. The only time disabled people and their minority

\footnotetext{
${ }^{9}$ Other philosophical references are made towards Ihde, Verbeek, Dreyfuss, Schön and even Brecht, showing that so far, theories on embodied computing are fundamentally based on the specific embodiments of European and North-American white men, even though alternatives exist (e.g., by Ahmed [2] or Wei-Ming [129]).
} 
bodyminds are referred to, they serve as a thought experiment for non-disabled people [90]. Their/our ${ }^{10}$ lived experiences are only relevant to support theories that centre their/our differences as deviating from the abstracted norm. In a similar vein, children, elderly, trans people, and black people are all loudly made absent as well, as their lived bodies comprise special cases for theoretical explorations, never the base.

Even though Cartesian mind/body splits are explicitly rejected by almost all papers, papers readily operate with or introduce ontological dualisms for analysis. Among these are dichotomies between acting and sensing [53], bodies and things [66] as well as Erfahrung and Erlebnis (as aspects of experience) [91]. Categorical differences appear to be more relevant to embodied computing than material differences in embodiment.

The singular static and ideal body assumed in theoretical contributions privileges experiences and aesthetic over an analysis of power and the implications of theories as well as technologies individually and collectively on diverse bodyminds. In that, there is a potential next step already inherent in this focus, as large strands of these works understand cognition and knowing as embodied, embodied computing could attend to the manifold potentials that the knowing of different bodyminds can bring to the field.

\section{DISCUSSION}

Across contribution types, I could identify norms that shape embodied computing at TEI more generally, which I critically detail before attending to the material consequences of these norms and the necessity of further theoretical explorations attending to these. To provide designers and researchers with a structure to reflect on their work along its potential normative assumptions, I close with a range of provocations for people working on embodied computing.

\subsection{The Bodies of TEI: Critical Perspectives}

There is no expectation that a single paper is attuned to all relevant axes of marginalisation to its particular topic. I am not exempt of this and have, as part of this analysis also critiqued my own prior work [120]. In attending to the normativising tendencies inherent across a larger set of papers, the TEI community can identify necessary future work diversifying and expanding our shared knowledge and design space on embodied computing.

5.1.1 The Singular Body. The descriptions of generalised human bodies in embodied computing is characterised by a notion of idealised bodies. Additionally, the dominant theories on embodied computing available so far and the current technological advances taken together appear to lead towards an almost disembodied notion of human bodies. When TEI talks about bodies, the community seems to shy away from embracing their messy realities in favour of a sanitised ideal that, ultimately, remains unachievable for everyone involved.

The main strategy to establish bodily norms generally and within the reviewed works is to not specify them, to leave them unmarked [14] and name only what is deemed other [25]. This strategy makes it very difficult to grasp these norms; they are not meant to be attainable and clear, they remain out of reach, which is why it is

\footnotetext{
${ }^{10}$ I took inspiration for this way of phrasing community within academic writing from Tuck and Yang [123].
}

so relevant to try and identify them. For example, when defining restraining and limiting bodily engagement through technologies as a playful resource aimed at enjoyment (e.g., [92]), designers imply that such 'limitations' are not already present and experienced similarly across different embodiments. When expecting people to move on their legs (e.g., [31]), those using scooters, wheelchairs and crutches implicitly remain out of focus. Unmarked norms in these works include a dominance of whiteness (across all 45 papers, only one [86] depicts a black body), (traditionally cis-male) flat-chestedness, slim bodies, presumably being reasonably well-off financially, and absence of any kind of disability. Only the 'minority body' [12] is marked, for example by being made explicit and assessed as a source in need of correction (e.g., [8]) towards a loosely defined unspecific norm.

To stay with the example of disability, the field of embodied computing could investigate how accessibility might look like when we account for differences in "felt experience". Given diverging modes of embodied cognition and sense-making for, e.g., autistic people [24], research could feasibly include an assessment of whether a specific material is tolerable or pleasant across individual bodyminds. For this, though, we will first need to establish a way of taking not just "the body as starting point" (in reference to [6]), but rather fundamentally thinking of bodies in the plural.

Throughout all contribution types, I found a persistent tendency to refer to 'the body' as a singular. However, even in cases where researchers and designers on embodied computing are envisioning single body-interactions, they rarely intend this to be the case for only one body. Speaking on the body in the singular "... hides the intricate complexity and diversity of bodies under a false universality ("the") and singleness ("body"). Thus, the image the phrase invokes is that of an abstract, adult, healthy, isolated, nondescript, typically male, typically white body. If we speak of bodies, instead, we immediately connote relations and plurality, at least leaving the door open to think them" [26, p.98]. Hence, I urge researchers on embodied computing at TEI and beyond to start talking about bodies as a plural as a first step towards accounting for a plurality of bodyminds.

5.1.2 Material Consequences. Next to opening the door of thinking about bodies in plurality, this plurality also needs to be actualised in research projects attending to difference in a productive manner. The call here is specifically not to just add more inquiries focused on specifically marginalised bodies (although those are also needed), but also further investigate how we may design for plurality and against normativising tendencies.

Across the corpus, papers have largely constructed embodied computing as a privileged project, one oriented on artful and reflective engagements. Without researchers actively attending to the messiness of human bodies and their lives, the non-ideal circumstances, this means that broader societal introductions of such technologies are shaped by capitalist commodification as has happened in the context of fitness trackers [118]. Next to using them explicitly as instruments of control in the context of health insurances [38], they also effectively exclude fat people through the design of wristbands [116] and keep large parts of the population using them anxious about not fitting ever slimming norms to the extent of actively enabling and supporting disordered eating behaviours 
[114]. The argument here is not that individual papers cause eating disorders, but rather that if the entirety of papers on embodied computing in the TEI community exclude such marginalised experiences (and others), we need to collectively reflect on how our work might contribute to these material effects.

But it is not just different body shapes that are conspicuously absent from embodied computing; the field also echoes the predominant norms of light skinned bodies. Hankerson et al. have already illustrated this for a range of technologies, including wearables, which do not entertain the possibility of wearers having dark skin [39]. However, even recent work illustrates how our design practices are fundamentally based on black markers on white skin leading to core design theme including the final prototype [85] As we do not consciously reflect on or even name the whiteness of our field, we perpetuate it as a norm. "To allow whiteness the power to go unnamed is to reinforce its status as given, as natural, as simply a site of being human" $[133, \mathrm{p} .45] .{ }^{11}$ It is not just the algorithms adding to dominant moves of oppression [15, 97], the material artefacts we produce are similarly not free from ideology. Hence, when we discuss the materiality of embodied computing and the experiences we make with materials [37], we need to go beyond the constrained context of our individual research projects and attend to the material consequences of our designs more within the larger field.

\subsection{Provocations for Embodied Interactions}

I close on a set of provocations for researchers and designers of embodied interaction that may guide them in interrogating the individual and collective norms inherent in their materials, designs, technologies and theories. These are meant to rattle and challenge our complicity with dominant power structures and as a starting point towards dismantling the oppressive norms implicitly and explicitly guiding our designs.

\section{Update theories.}

HCI thinks of bodies largely through phenomenological approaches of embodiment [78]. My suggestion here is not to "to dismiss a dominant approach and replace it with a new research agenda, epistemology and framing of the research" [107, p.85], but rather to expand the current set of theories informing our work which is dominated by phenomenology as propagated by white Western cis-men. Drawing in complementary perspectives and thickening our theoretical background will strengthen the contributions our field can make. Theoretical contributions often have an additional design or technology component (see Table 12), providing a productive playground for research into the designerly and material consequences of different theoretical backgrounds.

\section{Use plurals.}

I illustrated above how speaking about bodies in plurality might provide us with the more conscious opportunities to account for diverse embodiments [26]. However, using plurals can be productive beyond that. We might talk about the 'arts' of 'interactions', how

\footnotetext{
${ }^{11}$ As pointed out by Reviewer 3, though, racism is differently articulated and con ceptualised in different societies [59] and my analysis and interpretations here are fundamentally shaped by my own whiteness with associated problems thereof (see $[1])$.
}

'materials' shape the 'designs' and 'technologies' we work with and which 'theories' we draw on. Forcing ourselves to be open to plurality has the potential to consciously train us to think beyond static and singular norms.

\section{Check privileges.}

If the ideal body is the designers' body (as long as they are lightskinned, slim, and/or flat-chested), we need to reflect on our own embodiments and how they play a role in creating technologies for embodied interactions. As Höök reminds us that "somaesthetics (...) should not be dismissed as frivolous and confined to the art world" [49, p.191], but to counter such dismissal meaningfully, we need to actively account for the necessity and benefits of aesthetics in more marginalised contexts as well. To ask more pointedly ${ }^{12}$ : Where are the trans*, the crip, the fat, the queer, the indigenous, the black, the mad, the damaged, the sick, the old, the young, the dead, the sexual bodies in embodied computing?

\section{Forget intentions.}

A reflexive move to excuse ourselves from our complicity with normative powers is often to refer to 'good intentions'. Here, I dare researchers and designers in embodied computing to disregard their intent, listen to critique appreciatively and focus on the material effects of their work. In line with design justice pedagogies, we need to "prioritize design's impact on the community over the intentions of the designer" [21, p.193].

\section{Acknowledge imperfections.}

In that regard, I do not expect a single paper, designer or researcher (or group) to account for all matters of oppression in all of their research projects. However, when made aware of potentially critical issues embodied in their works, I encourage us to acknowledge failure gracefully. "The consequences of failing to understand our shortcomings in the diversity arena are programs and approaches that lead to claims of "the same old thing" and worse - shame and denial" [79]. Hence, only in acknowledging we have a problem, that our beings, our embodiments and with it our work and our actions are shaped by strong and dominant societal biases, we may start being accountable to them and exploring how to do better.

\section{Name norms.}

Another strategy lies in explicitly naming the normative tendencies shaping our work. This process is likely uncomfortable and difficult, as it is personal and oriented towards encountering imperfections we would rather not have head-on. However, it is ultimately my conviction that searching for and naming the normative tendencies, expectations and assumptions shaping our designs comprises only the first step towards encountering them and creating more equity related awareness. To stay with the example of whiteness, it is "the task for white subjects (...) to stay implicated in what they critique, but in turning towards their role and responsibility in (...) histories of racism, as histories of this present, to turn away from themselves, and towards others" [1].

\footnotetext{
${ }^{12}$ The question uses potentially offensive terms as positive (self) descriptors. These include the terms crip [20, 81], fat [109], queer [23], and mad [82].
} 


\section{Embrace messes.}

Living bodies are inherently messy. They sweat, they stumble, they swear. The bodily messes can serve as a reminder how we might choose restlessness over comfort, how our findings are constantly in flux and require regular (re)interpretation ${ }^{13}$. Embodied computing is full of politics, which are currently shaped more normatively and abstracting away from the inherent messiness of living. As a counter measure, we might consider taking up cyborg politics in embodied interactions. "Cyborg politics are the struggle for language and the struggle against perfect communication, against the one code that translates all meaning perfectly" [41, p.57] Acknowledging the assumptions inherent in work on embodied computing at TEI can only be a first step; a step we need to stay uncomfortable with productively opening up our field to make space for previously neglected knowledges, insights and designs.

\section{CONCLUSION}

With the somatic turn in Human-Computer Interaction [73], a critical investigation into the norms and assumptions in the design of embodied computing and interactions at TEI comprises a timely endeavour. Through a feminist content analysis of 45 papers spanning publication across 14 years since the inception of the conference, I illustrated inherent norms across material, designerly, technological, and theoretical contributions. I identified a fairly constrained set of represented bodies, generally normativising tendencies on expected embodiments, an implicitly imagined body ideal that is never made explicit, and a dominance of phenomenological theories. After discussing issues around 'the body' as a singular norm and the necessity of attending to material consequences of our design works more broadly, I offered a set of provocations that may serve designers and researchers interested in embodied interactions to reflect on how they may conduct their work going forward.

As any work, this analysis comes with limitations also shaped by my positionality. As a white researcher, my insights into the racialised lived experiences of BIPOC populations is necessarily limited. This has effects on my language and complicity in this white-dominated field, in which my critique is more easily attended to than those of non-white scholars whose perspective might be more relevant than mine. My theoretical and educational background further shaped our inquiries as well as my interpretative skills. Hence, I encourage researchers to use this corpus (or assemble their own) and add to my critical work here from their perspective, also at a later point to reflect on its impact. In future work, I intend to practically engage with the notions of designing against normativising tendencies and for plurality and diverse bodyminds and to theoretically broaden the base of how me might think of bodies in interactions; essentially, to take the work presented here as my own starting point to strive towards doing better than I have previously.

\section{"There are literally billions of different human bodies. We should beware of drawing general conclusions from their apparent universals." - [26, p.97]}

\footnotetext{
${ }^{13} \mathrm{I}$ are aware that this also means that my work here is already changed through the review and publication processes and the ways my readers interpret this work. I welcome your critique which may allow me to do better going forward.
}

\section{ACKNOWLEDGMENTS}

This work has been financially supported by the Austrian Science Fund (FWF) in the form of a Hertha-Firnberg scholarship (T 1146$\mathrm{G})$. My love goes out to all those who have contributed critique and feedback to this work formally and informally including the associate editor, reviewers 1, 2 and 3, Geraldine Fitzpatrick, Theresa J. Tanenbaum, Emeline Brulé, Rua Williams, Sabine Harrer, Eva Hornecker, Cale Passmore, Kearsley Schieder and David who was always ready for some jelly.

\section{REFERENCES}

[1] Sara Ahmed. 2004. Declarations of whiteness: The non-performativity of antiracism. borderlands 3, 2 (2004), 1-15.

[2] Sara Ahmed. 2006. Queer phenomenology: Orientations, objects, others. Duke University Press.

[3] Teresa Almeida, Rob Comber, and Madeline Balaam. 2016. HCI and Intimate Care as an Agenda for Change in Women's Health. In Proceedings of the 2016 CHI Conference on Human Factors in Computing Systems (San Jose, California, USA) (CHI '16). Association for Computing Machinery, New York, NY, USA, 2599-2611. https://doi.org/10.1145/2858036.2858187

[4] Nazanin Andalibi, Pinar Ozturk, and Andrea Forte. 2017. Sensitive SelfDisclosures, Responses, and Social Support on Instagram: The Case of \#Depression. In Proceedings of the 2017 ACM Conference on Computer Supported Cooperative Work and Social Computing (Portland, Oregon, USA) (CSCW'17). Association for Computing Machinery, New York, NY, USA, 1485-1500. https: //doi.org/10.1145/2998181.2998243

[5] Josh Andres, m.c. schraefel, Rakesh Patibanda, and Florian "Floyd" Mueller. 2020. Future InBodied: A Framework for Inbodied Interaction Design. In Proceedings of the Fourteenth International Conference on Tangible, Embedded, and Embodied Interaction (Sydney NSW, Australia) (TEI '20). Association for Computing Machinery, New York, NY, USA, 885-888. https://doi.org/10.1145/3374920.3374969

[6] Josh Andres, m.c. schraefel, Aaron Tabor, and Eric B. Hekler. 2019. The Body as Starting Point: Applying Inside Body Knowledge for Inbodied Design. In Extended Abstracts of the 2019 CHI Conference on Human Factors in Computing Systems (Glasgow, Scotland Uk) (CHI EA '19). Association for Computing Machinery, New York, NY, USA, 1-8. https://doi.org/10.1145/3290607.3299023

[7] B Lee Aultman. 2014. Cisgender. TSQ: Transgender Studies Quarterly 1, 1-2 (05 2014), 61-62. https://doi.org/10.1215/23289252-2399614 arXiv:https://read.dukeupress.edu/tsq/article-pdf/1/1-2/61/485886/19.pdf

[8] Naveen L. Bagalkot, Tomas Sokoler, and Riyaj Shaikh. 2012. Integrating Physiotherapy with Everyday Life: Exploring the Space of Possibilities through ReHandles. In Proceedings of the Sixth International Conference on Tangible, Embedded and Embodied Interaction (Kingston, Ontario, Canada) (TEI '12). Association for Computing Machinery, New York, NY, USA, 91-98. https: //doi.org/10.1145/2148131.2148152

[9] Jeffrey Bardzell and Shaowen Bardzell. 2015. Humanistic HCI. Synthesis Lectures on Human-Centered Informatics 8, 4 (2015), 1-185.

[10] Shaowen Bardzell. 2010. Feminist HCI: Taking Stock and Outlining an Agenda for Design. In Proceedings of the SIGCHI Conference on Human Factors in Computing Systems (Atlanta, Georgia, USA) (CHI '10). Association for Computing Machinery, New York, NY, USA, 1301-1310. https://doi.org/10.1145/1753326. 1753521

[11] Shaowen Bardzell and Jeffrey Bardzell. 2011. Towards a Feminist HCI Methodology: Social Science, Feminism, and HCI. In Proceedings of the SIGCHI Conference on Human Factors in Computing Systems (Vancouver, BC, Canada) (CHI '11). Association for Computing Machinery, New York, NY, USA, 675-684. https://doi.org/10.1145/1978942.1979041

[12] Elizabeth Barnes. 2016. The minority body: A theory of disability. Oxford University Press.

[13] Joanna Berzowska, Marc Beaulieu, Vincent Leclerc, Gaia Orain, Catherine Marchand, Catou Cournoyer, Emily Paris, Lois Frankel, and Miliana Sesartic. 2010. Captain Electric and Battery Boy: Prototypes for Wearable PowerGenerating Artifacts. In Proceedings of the Fourth International Conference on Tangible, Embedded, and Embodied Interaction (Cambridge, Massachusetts, USA) (TEI '10). Association for Computing Machinery, New York, NY, USA, 129-136. https://doi.org/10.1145/1709886.1709910

[14] Wayne Brekhus. 1998. A sociology of the unmarked: Redirecting our focus. Sociological Theory 16, 1 (1998), 34-51.

[15] Joy Buolamwini and Timnit Gebru. 2018. Gender shades: Intersectional accuracy disparities in commercial gender classification. In Conference on fairness, accountability and transparency. 77-91.

[16] Yves Candau, Jules Françoise, Sarah Fdili Alaoui, and Thecla Schiphorst. 2017. Cultivating Kinaesthetic Awareness through Interaction: Perspectives from 
Somatic Practices and Embodied Cognition. In Proceedings of the 4th International Conference on Movement Computing (London, United Kingdom) (MOCO '17). Association for Computing Machinery, New York, NY, USA, Article 21, 8 pages. https://doi.org/10.1145/3077981.3078042

[17] Yves Candau and Thecla Schiphorst. 2020. Pragmatic Circulations: John Dewey's Philosophy, Movement Practices and Embodied Cognition. In Proceedings of the 7th International Conference on Movement and Computing (Jersey City/Virtual, NJ, USA) (MOCO '20). Association for Computing Machinery, New York, NY, USA, Article 20, 8 pages. https://doi.org/10.1145/3401956.3404239

[18] Patrick Carrington, Kevin Chang, Helena Mentis, and Amy Hurst. 2015. "But, I Don't Take Steps": Examining the Inaccessibility of Fitness Trackers for Wheelchair Athletes. In Proceedings of the 17th International ACM SIGACCESS Conference on Computers \& Accessibility (Lisbon, Portugal) (ASSETS '15). Association for Computing Machinery, New York, NY, USA, 193-201. https://doi.org/10.1145/2700648.2809845

[19] Sharon Lynn Chu, Francis Quek, and Kumar Sridharamurthy. 2015. Augmenting Children's Creative Self-Efficacy and Performance through Enactment-Based Animated Storytelling. In Proceedings of the Ninth International Conference on Tangible, Embedded, and Embodied Interaction (Stanford, California, USA) (TEI '15). Association for Computing Machinery, New York, NY, USA, 209-216. https://doi.org/10.1145/2677199.2680602

[20] Eli Clare. 2017. Brilliant imperfection: Grappling with cure. Duke University Press.

[21] Sasha Costanza-Chock. 2020. Design justice: Community-led practices to build the worlds we need. MIT Press.

[22] Kimberle Crenshaw. 1990. Mapping the margins: Intersectionality, identity politics, and violence against women of color. Stan. L. Rev. 43 (1990), 1241

[23] Ulrika Dahl. 2014. Not gay as in happy, but queer as in fuck you. lambda nordica 19, 3-4 (2014), 143-168.

[24] Hanne De Jaegher. 2013. Embodiment and sense-making in autism. Frontiers in integrative neuroscience 7 (2013), 15.

[25] Fred Dervin. 2015. Discourses of othering. The international encyclopedia of language and social interaction (2015), 1-9.

[26] Ezequiel A Di Paolo, Elena Clare Cuffari, and Hanne De Jaegher. 2018. Linguistic bodies: The continuity between life and language. MIT Press.

[27] Christine Dierk, Sarah Sterman, Molly Jane Pearce Nicholas, and Eric Paulos. 2018. HäIrIÖ: Human Hair as Interactive Material. In Proceedings of the Twelfth International Conference on Tangible, Embedded, and Embodied Interaction (Stockholm, Sweden) (TEI '18). Association for Computing Machinery, New York, NY, USA, 148-157. https://doi.org/10.1145/3173225.3173232

[28] Paul Dourish. 2004. Where the action is: the foundations of embodied interaction MIT press.

[29] Jiachun Du, Panos Markopoulos, Qi Wang, Marina Toeters, and Ting Gong. 2018 ShapeTex: Implementing Shape-Changing Structures in Fabric for Wearable Actuation. In Proceedings of the Twelfth International Conference on Tangible, Embedded, and Embodied Interaction (Stockholm, Sweden) (TEI '18). Association for Computing Machinery, New York, NY, USA, 166-176. https://doi.org/10. $1145 / 3173225.3173245$

[30] Jochen Feitsch, Marco Strobel, Stefan Meyer, and Christian Geiger. 2014. Tan gible and Body-Related Interaction Techniques for a Singing Voice Synthesis Installation. In Proceedings of the 8th International Conference on Tangible, Embedded and Embodied Interaction (Munich, Germany) (TEI '14). Association for Computing Machinery, New York, NY, USA, 157-164. https: //doi.org/10.1145/2540930.2540962

[31] Frank Feltham, Lian Loke, Elise van den Hoven, Jeffrey Hannam, and Bert Bongers. 2014. The Slow Floor: Increasing Creative Agency While Walking on an Interactive Surface. In Proceedings of the 8th International Conference on Tangible, Embedded and Embodied Interaction (Munich, Germany) (TEI '14). Association for Computing Machinery, New York, NY, USA, 105-112. https: //doi.org/10.1145/2540930.2540974

[32] Rahel Flechtner, Katharina Lorenz, and Gesche Joost. 2020. Designing a Wearable Soft-Robotic Orthosis: A Body-Centered Approach. In Proceedings of the Fourteenth International Conference on Tangible, Embedded, and Embodied Inter action (Sydney NSW, Australia) (TEI '20). Association for Computing Machinery, New York, NY, USA, 863-875. https://doi.org/10.1145/3374920.3375012

[33] Maiken Hillerup Fogtmann, Jonas Fritsch, and Karen Johanne Kortbek. 2008 Kinesthetic Interaction: Revealing the Bodily Potential in Interaction Design. In Proceedings of the 20th Australasian Conference on Computer-Human Interaction Designing for Habitus and Habitat (Cairns, Australia) (OZCHI '08). Association for Computing Machinery, New York, NY, USA, 89-96. https://doi.org/10.1145/ 1517744.1517770

[34] Marie Galmiche, Pierre Déchelotte, Grégory Lambert, and Marie Pierre Tavolacci. 2019. Prevalence of eating disorders over the 2000-2018 period: a systematic literature review. The American fournal of Clinical Nutrition 109, 5 (04 2019), 1402-1413. https://doi.org/ 10.1093/ajcn/nqy342 arXiv:https://academic.oup.com/ajcn/articlepdf/109/5/1402/28888027/nqy342.pdf
[35] Renaud Gervais, Jérémy Frey, Alexis Gay, Fabien Lotte, and Martin Hachet. 2016. TOBE: Tangible Out-of-Body Experience. In Proceedings of the TEI '16: Tenth International Conference on Tangible, Embedded, and Embodied Interaction (Eindhoven, Netherlands) (TEI '16). Association for Computing Machinery, New York, NY, USA, 227-235. https://doi.org/10.1145/2839462.2839486

[36] Luc Geurts, Vero Vanden Abeele, Jelle Husson, Frederik Windey, Maarten Van Overveldt, Jan-Henk Annema, and Stef Desmet. 2010. Digital Games for Physical Therapy: Fulfilling the Need for Calibration and Adaptation. In Proceedings of the Fifth International Conference on Tangible, Embedded, and Embodied Interaction (Funchal, Portugal) (TEI '11). Association for Computing Machinery, New York, NY, USA, 117-124. https://doi.org/10.1145/1935701.1935725

[37] Elisa Giaccardi and Elvin Karana. 2015. Foundations of Materials Experience: An Approach for HCI. In Proceedings of the 33rd Annual ACM Conference on Human Factors in Computing Systems (Seoul, Republic of Korea) (CHI '15). Association for Computing Machinery, New York, NY, USA, 2447-2456. https://doi.org/10. $1145 / 2702123.2702337$

[38] Constantine Gidaris. 2019. Surveillance capitalism, datafication, and unwaged labour: the rise of wearable fitness devices and interactive life insurance. Surveillance \& Society 17, 1/2 (2019), 132-138.

[39] David Hankerson, Andrea R. Marshall, Jennifer Booker, Houda El Mimouni, Imani Walker, and Jennifer A. Rode. 2016. Does Technology Have Race?. In Proceedings of the 2016 CHI Conference Extended Abstracts on Human Factors in Computing Systems (San Jose, California, USA) (CHI EA '16). Association for Computing Machinery, New York, NY, USA, 473-486. https://doi.org/10.1145/ 2851581.2892578

[40] Donna Haraway. 1988. Situated knowledges: The science question in feminism and the privilege of partial perspective. Feminist studies 14, 3 (1988), 575-599.

[41] Donna J Haraway. 2016. Manifestly Haraway. Vol. 37. U of Minnesota Press.

[42] Daniel Harley, Alexander Verni, Mackenzie Willis, Ashley Ng, Lucas Bozzo, and Ali Mazalek. 2018. Sensory VR: Smelling, Touching, and Eating Virtual Reality. In Proceedings of the Twelfth International Conference on Tangible, Embedded, and Embodied Interaction (Stockholm, Sweden) (TEI '18). Association for Computing Machinery, New York, NY, USA, 386-397. https://doi.org/10.1145/3173225. 3173241

[43] Chris Harrison, Shilpa Ramamurthy, and Scott E. Hudson. 2012. On-Body Interaction: Armed and Dangerous. In Proceedings of the Sixth International Conference on Tangible, Embedded and Embodied Interaction (Kingston, Ontario, Canada) (TEI '12). Association for Computing Machinery, New York, NY, USA, 69-76. https://doi.org/10.1145/2148131.2148148

[44] Nancy CM Hartsock. 2017. The feminist standpoint: Developing the ground for a specifically feminist historical materialism. In Karl Marx. Routledge, 565-592.

[45] Julia Himmelsbach, Stephanie Schwarz, Cornelia Gerdenitsch, Beatrix WaisZechmann, Jan Bobeth, and Manfred Tscheligi. 2019. Do We Care About Diversity in Human Computer Interaction: A Comprehensive Content Analysis on Diversity Dimensions in Research. In Proceedings of the 2019 CHI Conference on Human Factors in Computing Systems (Glasgow, Scotland Uk) (CHI '19). Association for Computing Machinery, New York, NY, USA, 1-16. https://doi.org/10.1145/3290605.3300720

[46] Simon Holland, Anders J. Bouwer, Mathew Dalgelish, and Topi M. Hurtig. 2010. Feeling the Beat Where It Counts: Fostering Multi-Limb Rhythm Skills with the Haptic Drum Kit. In Proceedings of the Fourth International Conference on Tangible, Embedded, and Embodied Interaction (Cambridge, Massachusetts, USA) (TEI '10). Association for Computing Machinery, New York, NY, USA, 21-28. https://doi.org/10.1145/1709886.1709892

[47] Simon Holland, Paul Marshall, Jon Bird, Sheep Dalton, Richard Morris, Nadia Pantidi, Yvonne Rogers, and Andy Clark. 2009. Running up Blueberry Hill: Prototyping Whole Body Interaction in Harmony Space. In Proceedings of the $3 r d$ International Conference on Tangible and Embedded Interaction (Cambridge, United Kingdom) (TEI '09). Association for Computing Machinery, New York, NY, USA, 93-98. https://doi.org/10.1145/1517664.1517690

[48] Kristina Höök. 2010. Transferring Qualities from Horseback Riding to Design. In Proceedings of the 6th Nordic Conference on Human-Computer Interaction: Extending Boundaries (Reykjavik, Iceland) (NordiCHI '10). Association for Computing Machinery, New York, NY, USA, 226-235. https://doi.org/10.1145/1868914. 1868943

[49] Kristina Höök. 2018. Designing with the body: somaesthetic interaction design. MIT Press.

[50] Kristina Höök, Martin P. Jonsson, Anna Ståhl, and Johanna Mercurio. 2016. Somaesthetic Appreciation Design. In Proceedings of the 2016 CHI Conference on Human Factors in Computing Systems (San Jose, California, USA) (CHI '16). Association for Computing Machinery, New York, NY, USA, 3131-3142. https: //doi.org/10.1145/2858036.2858583

[51] Kristina Höök and Jonas Löwgren. 2012. Strong Concepts: Intermediate-Level Knowledge in Interaction Design Research. ACM Trans. Comput.-Hum. Interact. 19, 3, Article 23 (Oct. 2012), 18 pages. https://doi.org/10.1145/2362364.2362371

[52] Max Horkheimer. 1972. Critical theory: Selected essays. Vol. 1. A\&C Black.

[53] Caroline Hummels and Jelle van Dijk. 2015. Seven Principles to Design for Embodied Sensemaking. In Proceedings of the Ninth International Conference 
on Tangible, Embedded, and Embodied Interaction (Stanford, California, USA) (TEI '15). Association for Computing Machinery, New York, NY, USA, 21-28. https://doi.org/10.1145/2677199.2680577

[54] Ryan Ingebritsen, Christopher Knowlton, Hugh Sato, and Erica Mott. 2020 Social Movements: A Case Study in Dramaturgically-Driven Sound Design for Contemporary Dance Performance to Mediate Human-Human Interaction. In Proceedings of the Fourteenth International Conference on Tangible, Embedded, and Embodied Interaction (Sydney NSW, Australia) (TEI '20). Association for Computing Machinery, New York, NY, USA, 227-237. https://doi.org/10.1145/ 3374920.3374955

[55] Hiroshi Ishii. 2008. Tangible Bits: Beyond Pixels. In Proceedings of the 2nd International Conference on Tangible and Embedded Interaction (Bonn, Germany) (TEI '08). Association for Computing Machinery, New York, NY, USA, xv-xxv. https://doi.org/10.1145/1347390.1347392

[56] Hiroshi Ishii and Brygg Ullmer. 1997. Tangible Bits: Towards Seamless Interfaces between People, Bits and Atoms. In Proceedings of the ACM SIGCHI Conference on Human Factors in Computing Systems (Atlanta, Georgia, USA) (CHI '97) Association for Computing Machinery, New York, NY, USA, 234-241. https: //doi.org/10.1145/258549.258715

[57] Lee Jones, Sara Nabil, Amanda McLeod, and Audrey Girouard. 2020. Wearable Bits: Scaffolding Creativity with a Prototyping Toolkit for Wearable E-Textiles. In Proceedings of the Fourteenth International Conference on Tangible, Embedded, and Embodied Interaction (Sydney NSW, Australia) (TEI '20). Association for Computing Machinery, New York, NY, USA, 165-177. https://doi.org/10.1145/ 3374920.3374954

[58] Martin Jonsson, Anna Ståhl, Johanna Mercurio, Anna Karlsson, Naveen Ramani, and Kristina Höök. 2016. The Aesthetics of Heat: Guiding Awareness with Thermal Stimuli. In Proceedings of the TEI '16: Tenth International Conference on Tangible, Embedded, and Embodied Interaction (Eindhoven, Netherlands) (TEI '16). Association for Computing Machinery, New York, NY, USA, 109-117. https://doi.org/10.1145/2839462.2839487

[59] Yuko Kawai. 2015. Deracialised Race, Obscured Racism: Japaneseness, Western and Japanese Concepts of Race, and Modalities of Racism. Fapanese Studies 35, 1 (2015), 23-47. https://doi.org/10.1080/10371397.2015.1006598 arXiv:https://doi.org/10.1080/10371397.2015.1006598

[60] Os Keyes. 2018. The Misgendering Machines: Trans/HCI Implications of Automatic Gender Recognition. Proc. ACM Hum.-Comput. Interact. 2, CSCW, Article 88 (Nov. 2018), 22 pages. https://doi.org/10.1145/3274357

[61] Os Keyes, Burren Peil, Rua M. Williams, and Katta Spiel. 2020. Reimagining (Women's) Health: HCI, Gender and Essentialised Embodiment. ACM Trans. Comput.-Hum. Interact. 27, 4, Article 25 (July 2020), 42 pages. https://doi.org/ $10.1145 / 3404218$

[62] David Kirsh. 2013. Embodied Cognition and the Magical Future of Interaction Design. ACM Trans. Comput.-Hum. Interact. 20, 1, Article 3 (April 2013), 30 pages. https://doi.org/10.1145/2442106.2442109

[63] David Kirsh and Paul Maglio. 1994. On distinguishing epistemic from pragmatic action. Cognitive science 18, 4 (1994), 513-549.

[64] Rebecca Kleinberger and Alisha Panjwani. 2018. Digitally Enchanted Wear: A Novel Approach in the Field of Dresses as Dynamic Digital Displays. In Proceedings of the Twelfth International Conference on Tangible, Embedded, and Embodied Interaction (Stockholm, Sweden) (TEI '18). Association for Computing Machinery, New York, NY, USA, 27-34. https://doi.org/10.1145/3173225.3173250

[65] Scott R. Klemmer, Björn Hartmann, and Leila Takayama. 2006. How Bodies Matter: Five Themes for Interaction Design. In Proceedings of the 6th Conference on Designing Interactive Systems (University Park, PA, USA) (DIS '06). Association for Computing Machinery, New York, NY, USA, 140-149. https://doi.org/10. $1145 / 1142405.1142429$

[66] Astrid Twenebowa Larssen, Toni Robertson, and Jenny Edwards. 2007. The Feel Dimension of Technology Interaction: Exploring Tangibles through Movement and Touch. In Proceedings of the 1st International Conference on Tangible and Embedded Interaction (Baton Rouge, Louisiana) (TEI '07). Association for Computing Machinery, New York, NY, USA, 271-278. https://doi.org/10.1145/ 1226969.1227024

[67] Håkan Larsson. 2014. Materialising bodies: there is nothing more material than a socially constructed body. Sport, Education and Society 19, 5 (2014), 637-651. https://doi.org/10.1080/13573322.2012.722550 arXiv:https://doi.org/10.1080/13573322.2012.722550

[68] Michelle M. Lazar. 2014. Feminist Critical Discourse Analysis. John Wiley \& Sons, Ltd, Chapter 9, 180-199. https://doi.org/10.1002/9781118584248.ch9 arXiv:https://onlinelibrary.wiley.com/doi/pdf/10.1002/9781118584248.ch9

[69] Patricia Leavy. 2000. Feminist content analysis and representative characters The qualitative report 5, 1 (2000), 1-16.

[70] Patricia Leavy and Anne Harris. 2018. Contemporary feminist research from theory to practice. Guilford Publications.

[71] Conor Linehan, Sabine Harrer, Ben Kirman, Shaun Lawson, and Marcus Carter. 2015. Games Against Health: A Player-Centered Design Philosophy. In Proceedings of the 33rd Annual ACM Conference Extended Abstracts on Human
Factors in Computing Systems (Seoul, Republic of Korea) (CHI EA '15). Association for Computing Machinery, New York, NY, USA, 589-600. https: //doi.org/10.1145/2702613.2732514

[72] Lian Loke and Toni Robertson. 2013. Moving and Making Strange: An Embodied Approach to Movement-Based Interaction Design. ACM Trans. Comput.-Hum. Interact. 20, 1, Article 7 (April 2013), 25 pages. https://doi.org/10.1145/2442106. 2442113

[73] Lian Loke and Thecla Schiphorst. 2018. The Somatic Turn in Human-Computer Interaction. Interactions 25, 5 (Aug. 2018), 54-5863. https://doi.org/10.1145/ 3236675

[74] Judith Lorber and Patricia Yancey Martin. 2012. The socially constructed body. Illuminating social life: Classical and contemporary theory revisited (2012), 249.

[75] Deborah Lupton. 2014. Critical Perspectives on Digital Health Technologies. Sociology Compass 8, 12 (2014), 1344-1359. https://doi.org/10.1111/soc4.12226 arXiv:https://onlinelibrary.wiley.com/doi/pdf/10.1111/soc4.12226

[76] Jennifer Mankoff, Gillian R. Hayes, and Devva Kasnitz. 2010. Disability Studies as a Source of Critical Inquiry for the Field of Assistive Technology. In Proceedings of the 12th International ACM SIGACCESS Conference on Computers and Accessibility (Orlando, Florida, USA) (ASSETS '10). Association for Computing Machinery, New York, NY, USA, 3-10. https://doi.org/10.1145/1878803.1878807

[77] Elena Márquez Segura, Laia Turmo Vidal, Asreen Rostami, and Annika Waern. 2016. Embodied Sketching. In Proceedings of the 2016 CHI Conference on Human Factors in Computing Systems (San Jose, California, USA) (CHI '16). Association for Computing Machinery, New York, NY, USA, 6014-6027. https://doi.org/10. 1145/2858036.2858486

[78] Paul Marshall and Eva Hornecker. 2013. Theories of Embodiment in HCI. The SAGE handbook of digital technology research 1 (2013), 144-158.

[79] Peter C. Mather. 2008. Acknowledging Racism: Confronting Yourself. About Campus 13, 4 (2008), 27-29. https://doi.org/10.1002/abc.262 arXiv:https://doi.org/10.1002/abc.262

[80] Ali Mazalek, Sanjay Chandrasekharan, Michael Nitsche, Tim Welsh, Paul Clifton, Andrew Quitmeyer, Firaz Peer, Friedrich Kirschner, and Dilip Athreya. 2010. I'm in the Game: Embodied Puppet Interface Improves Avatar Control. In Proceedings of the Fifth International Conference on Tangible, Embedded, and Embodied Interaction (Funchal, Portugal) (TEI '11). Association for Computing Machinery, New York, NY, USA, 129-136. https://doi.org/10.1145/1935701.1935727

[81] Robert McRuer. 2006. Crip theory: Cultural signs of queerness and disability. Vol. 9. NYU press

[82] Brigit McWade, Damian Milton, and Peter Beresford. 2015. Mad studies and neurodiversity: A dialogue. Disability \& Society 30, 2 (2015), 305-309.

[83] Kobena Mercer. 2000. Black hair/style politics. Black British culture and society: A text reader (2000), 111-121.

[84] Jason Mickelson and Wendy Ju. 2010. Math Propulsion: Engaging Math Learners through Embodied Performance \& Visualization. In Proceedings of the Fifth International Conference on Tangible, Embedded, and Embodied Interaction (Funchal, Portugal) (TEI '11). Association for Computing Machinery, New York, NY, USA, 101-108. https://doi.org/10.1145/1935701.1935722

[85] Svetlana Mironcika, Annika Hupfeld, Joep Frens, Jessica Asjes, and Stephan Wensveen. 2020. Snap-Snap T-Shirt: Posture Awareness Through Playful and Somaesthetic Experience. In Proceedings of the Fourteenth International Conference on Tangible, Embedded, and Embodied Interaction (Sydney NSW, Australia) (TEI '20). Association for Computing Machinery, New York, NY, USA, 799-809. https://doi.org/10.1145/3374920.3375013

[86] Jin Moen. 2007. From Hand-Held to Body-Worn: Embodied Experiences of the Design and Use of a Wearable Movement-Based Interaction Concept. In Proceedings of the 1st International Conference on Tangible and Embedded Interaction (Baton Rouge, Louisiana) (TEI '07). Association for Computing Machinery, New York, NY, USA, 251-258. https://doi.org/10.1145/1226969.1227021

[87] Florian Floyd Mueller, Pedro Lopes, Paul Strohmeier, Wendy Ju, Caitlyn Seim, Martin Weigel, Suranga Nanayakkara, Marianna Obrist, Zhuying Li, Joseph Delfa, Jun Nishida, Elizabeth M. Gerber, Dag Svanaes, Jonathan Grudin, Stefan Greuter, Kai Kunze, Thomas Erickson, Steven Greenspan, Masahiko Inami, Joe Marshall, Harald Reiterer, Katrin Wolf, Jochen Meyer, Thecla Schiphorst, Dakuo Wang, and Pattie Maes. 2020. Next Steps for Human-Computer Integration. In Proceedings of the $2020 \mathrm{CHI}$ Conference on Human Factors in Computing Systems (Honolulu, HI, USA) (CHI '20). Association for Computing Machinery, New York, NY, USA, 1-15. https://doi.org/10.1145/3313831.3376242

[88] Florian "Floyd" Mueller, Richard Byrne, Josh Andres, and Rakesh Patibanda. 2018. Experiencing the Body as Play. In Proceedings of the 2018 CHI Conference on Human Factors in Computing Systems (Montreal QC, Canada) (CHI '18). Association for Computing Machinery, New York, NY, USA, 1-13. https://doi. org/10.1145/3173574.3173784

[89] Florian "Floyd" Mueller, Martin Gibbs, Frank Vetere, Stefan Agamanolis, and Darren Edge. 2014. Designing Mediated Combat Play. In Proceedings of the 8th International Conference on Tangible, Embedded and Embodied Interaction (Munich, Germany) (TEI '14). Association for Computing Machinery, New York, NY, USA, 149-156. https://doi.org/10.1145/2540930.2540937 
[90] Florian "Floyd" Mueller, Tuomas Kari, Zhuying Li, Yan Wang, Yash Dhanpal Mehta, Josh Andres, Jonathan Marquez, and Rakesh Patibanda. 2020. Towards Designing Bodily Integrated Play. In Proceedings of the Fourteenth International Conference on Tangible, Embedded, and Embodied Interaction (Sydney NSW, Australia) (TEI '20). Association for Computing Machinery, New York, NY, USA, 207-218. https://doi.org/10.1145/3374920.3374931

[91] Florian "Floyd" Mueller, Louise Matjeka, Yan Wang, Josh Andres, Zhuying Li, Jonathan Marquez, Bob Jarvis, Sebastiaan Pijnappel, Rakesh Patibanda, and Rohit Ashok Khot. 2020. "Erfahrung \& Erlebnis": Understanding the Bodily Play Experience through German Lexicon. In Proceedings of the Fourteenth Inter national Conference on Tangible, Embedded, and Embodied Interaction (Sydney NSW, Australia) (TEI '20). Association for Computing Machinery, New York, NY, USA, 337-347. https://doi.org/10.1145/3374920.3374926

[92] Florian "Floyd" Mueller, Yan Wang, Zhuying Li, Tuomas Kari, Peter Arnold, Yash Dhanpal Mehta, Jonathan Marquez, and Rohit Ashok Khot. 2020. Towards Experiencing Eating as Play. In Proceedings of the Fourteenth International Conference on Tangible, Embedded, and Embodied Interaction (Sydney NSW, Australia) (TEI '20). Association for Computing Machinery, New York, NY, USA, 239-253. https://doi.org/10.1145/3374920.3374930

[93] Hye Yeon Nam and Michael Nitsche. 2014. Interactive Installations as Per formance: Inspiration for HCI. In Proceedings of the 8th International Conference on Tangible, Embedded and Embodied Interaction (Munich, Germany) (TEI '14). Association for Computing Machinery, New York, NY, USA, 189-196. https://doi.org/10.1145/2540930.2540976

[94] William L. Neuman. 1997. Social Research Methods: Qualitative and Quantitative Approaches. Allyn and Bacon. https://books.google.at/books?id=rKL9lgWN $1 \mathrm{gC}$

[95] Gary Ng, Joon Gi Shin, Alexander Plopski, Christian Sandor, and Daniel Saakes. 2018. Situated Game Level Editing in Augmented Reality. In Proceedings of the Twelfth International Conference on Tangible, Embedded, and Embodied Interaction (Stockholm, Sweden) (TEI '18). Association for Computing Machinery, New York, NY, USA, 409-418. https://doi.org/10.1145/3173225.3173230

[96] Mahdi G Nia, Mehdi F Harandi, and Marc J de Vries. 2019. Technology Development as a Normative Practice: A Meaning-Based Approach to Learning About Values in Engineering-Damming as a Case Study. Science and engineering ethics 25, 1 (2019), 55-82.

[97] Safiya Umoja Noble. 2018. Algorithms of oppression: How search engines reinforce racism. NYU Press.

[98] James I. Novak. 2020. Awareables: Beyond Wearable Technology. In Proceedings of the Fourteenth International Conference on Tangible, Embedded, and Embodied Interaction (Sydney NSW, Australia) (TEI '20). Association for Computing Machinery, New York, NY, USA, 5-16. https://doi.org/10.1145/3374920.3374925

[99] Claudia Núñez Pacheco and Lian Loke. 2017. Tacit Narratives: Surfacing Aesthetic Meaning by Using Wearable Props and Focusing. In Proceedings of the Eleventh International Conference on Tangible, Embedded, and Embodied Interaction (Yokohama, Japan) (TEI '17). Association for Computing Machinery, New York, NY, USA, 233-242. https://doi.org/10.1145/3024969.3024979

[100] Claudia Nunez-Pacheco and Lian Loke. 2014. Crafting the Body-Tool: A Body-Centred Perspective on Wearable Technology. In Proceedings of the 2014 Conference on Designing Interactive Systems (Vancouver, BC, Canada) (DIS 14). Association for Computing Machinery, New York, NY, USA, 553-566. https://doi.org/10.1145/2598510.2598546

[101] Ihudiya Finda Ogbonnaya-Ogburu, Angela D.R. Smith, Alexandra To, and Kentaro Toyama. 2020. Critical Race Theory for HCI. In Proceedings of the 2020 CHI Conference on Human Factors in Computing Systems (Honolulu, HI, USA) (CHI '20). Association for Computing Machinery, New York, NY, USA, 1-16. https://doi.org/10.1145/3313831.3376392

[102] Isabel Pedersen and Andrew Iliadis. 2020. Embodied Computing: Wearables, Implantables, Embeddables, Ingestibles. MIT Press.

[103] Sebastiaan Pijnappel and Florian "Floyd" Mueller. 2014. Designing Interactive Technology for Skateboarding. In Proceedings of the 8th International Conference on Tangible, Embedded and Embodied Interaction (Munich, Germany) (TEI '14). Association for Computing Machinery, New York, NY, USA, 141-148. https: //doi.org/10.1145/2540930.2540950

[104] Aura Pon, Eric Pattison, Lawrence Fyfe, Laurie Radford, and Sheelagh Carpendale. 2017. Torrent: Integrating Embodiment, Physicalization and Musification in Music-Making. In Proceedings of the Eleventh International Conference on Tangible, Embedded, and Embodied Interaction (Yokohama, Japan) (TEI '17). Association for Computing Machinery, New York, NY, USA, 209-216. https://doi.org/10.1145/3024969.3024974

[105] Gisela Reyes-Cruz, Joel E. Fischer, and Stuart Reeves. 2020. Reframing Disability as Competency: Unpacking Everyday Technology Practices of People with Visual Impairments. In Proceedings of the 2020 CHI Conference on Human Factors in Computing Systems (Honolulu, HI, USA) (CHI '20). Association for Computing Machinery, New York, NY, USA, 1-13. https://doi.org/10.1145/3313831.3376767

[106] Jennifer A. Rode. 2011. A theoretical agenda for feminist HCI. Interacting with Computers 23, 5 (2011), 393-400.
[107] Yvonne Rogers. 2012. HCI theory: classical, modern, and contemporary. Synthesis lectures on human-centered informatics 5, 2 (2012), 1-129.

[108] Asreen Rostami, Donald McMillan, Elena Márquez Segura, Chiara Rossito, and Louise Barkhuus. 2017. Bio-Sensed and Embodied Participation in Interactive Performance. In Proceedings of the Eleventh International Conference on Tangible, Embedded, and Embodied Interaction (Yokohama, Japan) (TEI '17). Association for Computing Machinery, New York, NY, USA, 197-208. https://doi.org/10. $1145 / 3024969.3024998$

[109] Esther D Rothblum and Sondra Solovay. 2009. The fat studies reader. NYU Press.

[110] Sami Schalk. 2018. Bodyminds reimagined:(Dis) ability, race, and gender in Black women's speculative fiction. Duke University Press.

[111] Marie-Monique Schaper and Narcis Pares. 2016. Making Sense of Body and Space through Full-Body Interaction Design: A Case Study. In Proceedings of the The 15th International Conference on Interaction Design and Children (Manchester, United Kingdom) (IDC '16). Association for Computing Machinery, New York, NY, USA, 613-618. https://doi.org/10.1145/2930674.2935992

[112] Thecla Schiphorst, Frank Nack, Michiel KauwATjoe, Simon de Bakker, Stock, Lora Aroyo, Angel Perez Rosillio, Hielke Schut, and Norm Jaffe. 2007. PillowTalk: Can We Afford Intimacy?. In Proceedings of the 1st International Conference on Tangible and Embedded Interaction (Baton Rouge, Louisiana) (TEI '07). Association for Computing Machinery, New York, NY, USA, 23-30. https://doi.org/10.1145/1226969.1226975

[113] Dennis Schleicher, Peter Jones, and Oksana Kachur. 2010. Bodystorming as Embodied Designing. Interactions 17, 6 (Nov. 2010), 47-51. https://doi.org/10. $1145 / 1865245.1865256$

[114] Courtney C. Simpson and Suzanne E. Mazzeo. 2017. Calorie counting and fitness tracking technology: Associations with eating disorder symptomatology. Eating Behaviors 26 (2017), 89 - 92. https://doi.org/10.1016/j.eatbeh.2017.02.002

[115] Dorothé Smit, Doenja Oogjes, Bruna Goveia de Rocha, Ambra Trotto, Yeup Hur, and Caroline Hummels. 2016. Ideating in Skills: Developing Tools for Embodied Co-Design. In Proceedings of the TEI '16: Tenth International Conference on Tangible, Embedded, and Embodied Interaction (Eindhoven, Netherlands) (TEI '16). Association for Computing Machinery, New York, NY, USA, 78-85. https://doi.org/10.1145/2839462.2839497

[116] Katta Spiel. 2019. Body-Positive Computing as a Means to Counteract Normative Biases in Fitness Trackers. XRDS 25, 4 (July 2019), 34-37. https://doi.org/10. 1145/3331065

[117] Katta Spiel and Kathrin Gerling. 2019. The Surrogate Body in Play. In Proceedings of the Annual Symposium on Computer-Human Interaction in Play (Barcelona, Spain) (CHI PLAY '19). Association for Computing Machinery, New York, NY, USA, 397-411. https://doi.org/10.1145/3311350.3347189

[118] Katta Spiel, Fares Kayali, Louise Horvath, Michael Penkler, Sabine Harrer, Miguel Sicart, and Jessica Hammer. 2018. Fitter, Happier, More Productive? The Normative Ontology of Fitness Trackers. In Extended Abstracts of the 2018 CHI Conference on Human Factors in Computing Systems (Montreal QC, Canada) (CHI EA '18). Association for Computing Machinery, New York, NY, USA, 1-10. https://doi.org/10.1145/3170427.3188401

[119] Katta Spiel, Os Keyes, and Pınar Barlas. 2019. Patching Gender: Non-Binary Utopias in HCI. In Extended Abstracts of the 2019 CHI Conference on Human Factors in Computing Systems (Glasgow, Scotland Uk) (CHI EA '19). Association for Computing Machinery, New York, NY, USA, 1-11. https://doi.org/10.1145/ 3290607.3310425

[120] Katta Spiel, Julia Makhaeva, and Christopher Frauenberger. 2016. Embodied Companion Technologies for Autistic Children. In Proceedings of the TEI '16: Tenth International Conference on Tangible, Embedded, and Embodied Interaction (Eindhoven, Netherlands) (TEI '16). Association for Computing Machinery, New York, NY, USA, 245-252. https://doi.org/10.1145/2839462.2839495

[121] Dag Svanæs. 2013. Interaction Design for and with the Lived Body: Some Implications of Merleau-Ponty's Phenomenology. ACM Trans. Comput.-Hum. Interact. 20, 1, Article 8 (April 2013), 30 pages. https://doi.org/10.1145/2442106. 2442114

[122] Vasiliki Tsaknaki and Ludvig Elblaus. 2019. A Wearable Nebula Material Investigations of Implicit Interaction. In Proceedings of the Thirteenth International Conference on Tangible, Embedded, and Embodied Interaction (Tempe, Arizona, USA) (TEI '19). Association for Computing Machinery, New York, NY, USA, 625-633. https://doi.org/10.1145/3294109.3295623

[123] Eve Tuck and K Wayne Yang. 2012. Decolonization is not a metaphor. Decolonization: Indigeneity, education \& society 1,1 (2012).

[124] Laia Turmo Vidal, Elena Márquez Segura, Luis Parrilla Bel, and Annika Waern. 2020. Training Body Awareness and Control with Technology Probes: A Portfolio of Co-Creative Uses to Support Children with Motor Challenges. In Proceedings of the Fourteenth International Conference on Tangible, Embedded, and Embodied Interaction (Sydney NSW, Australia) (TEI '20). Association for Computing Machinery, New York, NY, USA, 823-835. https://doi.org/10.1145/3374920.3375002

[125] Jelle van Dijk and Caroline Hummels. 2017. Designing for Embodied Being-inthe-World: Two Cases, Seven Principles and One Framework. In Proceedings of the Eleventh International Conference on Tangible, Embedded, and Embodied Interaction (Yokohama, Japan) (TEI '17). Association for Computing Machinery, 
New York, NY, USA, 47-56. https://doi.org/10.1145/3024969.3025007

[126] Jelle van Dijk, Remko van der Lugt, and Caroline Hummels. 2014. Beyond Distributed Representation: Embodied Cognition Design Supporting SocioSensorimotor Couplings. In Proceedings of the 8th International Conference on Tangible, Embedded and Embodied Interaction (Munich, Germany) (TEI '14). Association for Computing Machinery, New York, NY, USA, 181-188. https: //doi.org/10.1145/2540930.2540934

[127] Maarten Versteeg, Elise van den Hoven, and Caroline Hummels. 2016. Interactive Jewellery: A Design Exploration. In Proceedings of the TEI '16: Tenth International Conference on Tangible, Embedded, and Embodied Interaction (Eindhoven, Netherlands) (TEI '16). Association for Computing Machinery, New York, NY, USA, 44-52. https://doi.org/10.1145/2839462.2839504

[128] Wouter Walmink, Danielle Wilde, and Florian "Floyd" Mueller. 2014. Displaying Heart Rate Data on a Bicycle Helmet to Support Social Exertion Experiences. In Proceedings of the 8th International Conference on Tangible, Embedded and Embodied Interaction (Munich, Germany) (TEI '14). Association for Computing Machinery, New York, NY, USA, 97-104. https://doi.org/10.1145/2540930.2540970

[129] Tu Wei-Ming. 1992. A Confucian Perspective on Embodiment. Springer Netherlands, Dordrecht, 87-100. https://doi.org/10.1007/978-94-015-7924-7_6

[130] Anusha Withana, Daniel Groeger, and Jürgen Steimle. 2018. Tacttoo: A Thin and Feel-Through Tattoo for On-Skin Tactile Output. In Proceedings of the 31st Annual ACM Symposium on User Interface Software and Technology (Berlin
Germany) (UIST '18). Association for Computing Machinery, New York, NY, USA, 365-378. https://doi.org/10.1145/3242587.3242645

[131] Jacob O. Wobbrock and Julie A. Kientz. 2016. Research Contributions in HumanComputer Interaction. Interactions 23, 3 (April 2016), 38-44. https://doi.org/10. 1145/2907069

[132] Björn Wöldecke, Tom Vierjahn, Matthias Flasko, Jens Herder, and Christian Geiger. 2009. Steering Actors through a Virtual Set Employing Vibro-Tactile Feedback. In Proceedings of the 3rd International Conference on Tangible and Embedded Interaction (Cambridge, United Kingdom) (TEI '09). Association for Computing Machinery, New York, NY, USA, 169-174. https://doi.org/10.1145/ 1517664.1517703

[133] George Yancy. 2008. Black bodies, white gazes: The continuing significance of race in America. Rowman \& Littlefield.

[134] Anon Ymous, Katta Spiel, Os Keyes, Rua M. Williams, Judith Good, Eva Hornecker, and Cynthia L. Bennett. 2020. "I Am Just Terrified of My Future" Epistemic Violence in Disability Related Technology Research. In Extended Abstracts of the 2020 CHI Conference on Human Factors in Computing Systems (Honolulu, HI, USA) (CHI EA '20). Association for Computing Machinery, New York, NY, USA, 1-16. https://doi.org/10.1145/3334480.3381828

\section{A APPENDIX}




\begin{tabular}{|c|c|c|c|c|}
\hline Paper & Year & Title & keywords & $\mathrm{C} 2$ \\
\hline Jonsson et al. [58] & 2016 & $\begin{array}{l}\text { The Aesthetics of Heat: Guiding Awareness } \\
\text { with Thermal Stimuli }\end{array}$ & $\begin{array}{l}\text { Thermal stimuli; heat; somaesthetics; body awareness; } \\
\text { aesthetics }\end{array}$ & - \\
\hline Smit et al. [115] & 2016 & $\begin{array}{l}\text { Ideating in Skills: Developing Tools for Em- } \\
\text { bodied Co-Design }\end{array}$ & $\begin{array}{l}\text { design tools; multi-stakeholder processes; ideation; em- } \\
\text { bodiment; ideating in skills }\end{array}$ & design \\
\hline Dierk et al. [27] & 2018 & HäirIÖ: Human Hair as Interactive Material & wearables; cosmetic computing; ambient displays; hair & - \\
\hline Du et al. [29] & 2018 & $\begin{array}{l}\text { ShapeTex: Implementing Shape-Changing } \\
\text { Structures in Fabric for Wearable Actuation }\end{array}$ & $\begin{array}{l}\text { Shape-Changing Interface; Thermal Transformation; } \\
\text { Wearable Actuation; Material Design }\end{array}$ & - \\
\hline Jones et al. [57] & 2020 & $\begin{array}{l}\text { Wearable Bits - Scaffolding Creativity with a } \\
\text { Prototyping Toolkit for Wearable E-textiles }\end{array}$ & $\begin{array}{l}\text { e-textile; smart clothing; wearable; constructive assem- } \\
\text { bly; toolkit; fidelity; prototype; co-design }\end{array}$ & design \\
\hline
\end{tabular}

Table 7: Papers making a material contribution within the corpus. C2 refers to the secondary contribution made, if applicable.

\begin{tabular}{|c|c|c|c|c|c|}
\hline Paper & Year & Title & keywords & $\mathrm{C} 2$ & $\mathrm{SC}$ \\
\hline Moen [86] & 2007 & $\begin{array}{l}\text { From Hand-Held to Body Worn: Embod- } \\
\text { ied Experiences of Design and Use of a } \\
\text { Wearable Movement-Based Interaction } \\
\text { Concept }\end{array}$ & $\begin{array}{l}\text { Movement quality, movement-based interaction, } \\
\text { kinesthetics, wearable artifacts, embodied inter- } \\
\text { action, social context of use }\end{array}$ & theory & Case Study \\
\hline $\begin{array}{l}\text { Berzowska et al. } \\
{[13]}\end{array}$ & 2010 & $\begin{array}{l}\text { Captain Electric and Battery Boy: Pro- } \\
\text { totypes for Wearable Power-Generating } \\
\text { Artifacts }\end{array}$ & $\begin{array}{l}\text { Human generated power, electronic garments, } \\
\text { wearable technology }\end{array}$ & - & Exploration \\
\hline Bagalkot et al. [8] & 2012 & $\begin{array}{l}\text { Integrating Physiotherapy with Every- } \\
\text { day Life: Exploring the Space of Possibil- } \\
\text { ities through ReHandles }\end{array}$ & $\begin{array}{l}\text { Concept Driven IxD Research, Speculative design, } \\
\text { Design space, Physiotherapy, Embodied Interac- } \\
\text { tion, Physical rehabilitation, Sketching. }\end{array}$ & - & Case Study \\
\hline $\begin{array}{ll}\text { Pijnappel } & \text { and } \\
\text { Mueller [103] }\end{array}$ & 2014 & $\begin{array}{l}\text { Designing Interactive Technology for } \\
\text { Skateboarding }\end{array}$ & $\begin{array}{l}\text { Skateboarding; exertion games; trick-focused } \\
\text { sports }\end{array}$ & technology & Case Study \\
\hline $\begin{array}{l}\text { Hummels and van } \\
\text { Dijk [53] }\end{array}$ & 2015 & $\begin{array}{l}\text { Seven Principles to Design for Embodied } \\
\text { Sensemaking }\end{array}$ & $\begin{array}{l}\text { Sensemaking; embodiment; social coordination; } \\
\text { tangible interaction; communication; design pro- } \\
\text { cess }\end{array}$ & theory & Guidance \\
\hline Smit et al. [115] & 2016 & $\begin{array}{l}\text { Ideating in Skills: Developing Tools for } \\
\text { Embodied Co-Design }\end{array}$ & $\begin{array}{l}\text { design tools; multi-stakeholder processes; } \\
\text { ideation; embodiment; ideating in skills }\end{array}$ & material & Guidance \\
\hline Versteeg et al. [127] & 2016 & $\begin{array}{l}\text { Interactive Jewellery: a design explo- } \\
\text { ration }\end{array}$ & $\begin{array}{l}\text { Tangible interaction; interactive jewellery; auto- } \\
\text { biographical memory; memento }\end{array}$ & - & Exploration \\
\hline $\begin{array}{l}\text { van Dijk and Hum- } \\
\text { mels [125] }\end{array}$ & 2017 & $\begin{array}{l}\text { Designing for Embodied Being-in-the- } \\
\text { World: Two Cases, Seven Principles and } \\
\text { One Framework }\end{array}$ & $\begin{array}{l}\text { Embodied Being-in-the-World; assistive technol- } \\
\text { ogy; empowerment; tangible interaction; ubiqui- } \\
\text { tous computing }\end{array}$ & theory & Guidance \\
\hline Pon et al. [104] & 2017 & $\begin{array}{l}\text { Torrent: Integrating Embodiment, Phys- } \\
\text { icalization and Musification in Music- } \\
\text { Making }\end{array}$ & $\begin{array}{l}\text { Electroacoustic Music; Embodied Interaction; } \\
\text { Physicalization; Musification; Electromyography }\end{array}$ & technology & Case Study \\
\hline Rostami et al. [108] & 2017 & $\begin{array}{l}\text { Bio-Sensed and Embodied Participation } \\
\text { in Interactive Performance }\end{array}$ & $\begin{array}{l}\text { Interactive performances; Bio-Sensing; Audience } \\
\text { Engagement; Bodily tracking; Biodata }\end{array}$ & - & Exploration \\
\hline Ng et al. [95] & 2018 & $\begin{array}{l}\text { Situated Game Level editing in Aug- } \\
\text { mented Reality }\end{array}$ & $\begin{array}{l}\text { Augmented Reality; Game Design; Level Editor; } \\
\text { Spatial Programming; Trigger-Action Program- } \\
\text { ming }\end{array}$ & - & Case Study \\
\hline $\begin{array}{ll}\text { Tsaknaki } & \text { and } \\
\text { Elblaus [122] } & \end{array}$ & 2019 & $\begin{array}{l}\text { A Wearable Nebula - Material Investiga- } \\
\text { tions of Implicit Interaction }\end{array}$ & $\begin{array}{l}\text { Implicit Interaction; Wearable technology; Craft- } \\
\text { ing; Sound and Music Computing; Materials }\end{array}$ & technology & Case Study \\
\hline Flechtner et al. [32] & 2020 & $\begin{array}{l}\text { Designing a Wearable Soft-Robotic Or- } \\
\text { thosis: A Body-Centred Approach }\end{array}$ & $\begin{array}{l}\text { Soft Robotics; Body-Centered Design; Bodys- } \\
\text { torming; Participatory Design; Orthotics; Human } \\
\text { Machine interaction }\end{array}$ & technology & Case Study \\
\hline $\begin{array}{l}\text { Ingebritsen et al. } \\
\text { [54] }\end{array}$ & 2020 & $\begin{array}{l}\text { Social Movements: A Case Study in } \\
\text { Dramaturgically-Driven Sound Design } \\
\text { for Contemporary Dance Performance } \\
\text { to Mediate Human-Human Interaction }\end{array}$ & $\begin{array}{l}\text { digital musical instruments; kinesthetic empa- } \\
\text { thy; sonification; contemporary dance; audience } \\
\text { participation }\end{array}$ & technology & Case Study \\
\hline
\end{tabular}

Table 8: Papers making a design contribution within the corpus. $\mathrm{C} 2$ refers to the secondary contribution made, if applicable, SC refers to the subcontribution made (1/2). 


\begin{tabular}{|c|c|c|c|c|c|}
\hline Paper & Year & Title & keywords & $\mathrm{C} 2$ & SC \\
\hline Jones et al. [57] & 2020 & $\begin{array}{l}\text { Wearable Bits - Scaffolding Creativity } \\
\text { with a Prototyping Toolkit for Wearable } \\
\text { E-textiles }\end{array}$ & $\begin{array}{l}\text { e-textile; smart clothing; wearable; constructive } \\
\text { assembly; toolkit; fidelity; prototype; co-design }\end{array}$ & material & Guidance \\
\hline Mironcika et al. [85] & 2020 & $\begin{array}{l}\text { Snap-Snap T-Shirt: Posture Awareness } \\
\text { Through Playful and Somaesthetic Expe- } \\
\text { rience }\end{array}$ & $\begin{array}{l}\text { Posture awareness; RSI; co-design; garment; per- } \\
\text { sonalization; somaesthetics; playfulness; move- } \\
\text { ment observation; magnets. }\end{array}$ & - & Case Study \\
\hline Mueller et al. [92] & 2020 & Towards Experiencing Eating as Play & $\begin{array}{l}\text { Food; Eating; Human-Food Interaction; FoodCHI; } \\
\text { Play }\end{array}$ & technology & Guidance \\
\hline $\begin{array}{l}\text { Turmo Vidal et al. } \\
\text { [124] }\end{array}$ & 2020 & $\begin{array}{l}\text { Training Body Awareness and Control } \\
\text { with Technology Probes: A Portfolio of } \\
\text { Co-Creative Uses to Support Children } \\
\text { with Motor Challenges }\end{array}$ & $\begin{array}{l}\text { Physical Training; Technology Probes; Co- } \\
\text { Creation; Children; Somatic Exploration; Circus; } \\
\text { Body Awareness }\end{array}$ & technology & Guidance \\
\hline
\end{tabular}

Table 9: Papers making a design contribution within the corpus. C2 refers to the secondary contribution made, if applicable, $S C$ refers to the subcontribution made $(2 / 2)$.

\begin{tabular}{|c|c|c|c|c|c|}
\hline Paper & Year & Title & keywords & $\mathrm{C} 2$ & SC \\
\hline $\begin{array}{l}\text { Schiphorst et al. } \\
\text { [112] }\end{array}$ & 2007 & PillowTalk: Can We Afford Intimacy? & $\begin{array}{l}\text { social intimacy, tactile interface, somatics, move- } \\
\text { ment analysis, Laban effort-shape, tangible UIs, } \\
\text { art/design installation, play, social interaction, user } \\
\text { experience, ambient environment, choreography } \\
\text { of interaction }\end{array}$ & - & $\mathrm{F} \& \mathrm{R}$ \\
\hline Holland et al. [47] & 2009 & $\begin{array}{l}\text { Running up Blueberry Hill: Prototyping } \\
\text { Whole Body Interaction in Harmony Space }\end{array}$ & $\begin{array}{l}\text { Harmony Space, whole body interaction, embodi- } \\
\text { ment, music }\end{array}$ & - & $M \& A$ \\
\hline $\begin{array}{l}\text { Wöldecke et al. } \\
\text { [132] }\end{array}$ & 2009 & $\begin{array}{l}\text { Steering Actors Through A Virtual Set - Em- } \\
\text { ploying Vibor-Tactile Feedback }\end{array}$ & $\begin{array}{l}\text { tactile feedback, interaction in virtual sets, naviga- } \\
\text { tion aids }\end{array}$ & - & $M \& A$ \\
\hline Holland et al. [46] & 2010 & $\begin{array}{l}\text { Felling the Beat Where it Counts: Fostering } \\
\text { Multi-Limb Rhythm Skills with the Haptic } \\
\text { Drum Kit }\end{array}$ & $\begin{array}{l}\text { Haptic Drum Kit, haptic interaction, vibrotac- } \\
\text { tile, Dalcroze, drumming, multi-limb coordination, } \\
\text { rhythm, polyphonic rhythm, guidance, instruction, } \\
\text { entrainment, embodied cognition, sensory motor } \\
\text { contingency, temporal patterns }\end{array}$ & - & $M \& A$ \\
\hline Geurts et al. [36] & 2011 & $\begin{array}{l}\text { Digital Games for Physical Therapy: Fulfilling } \\
\text { the Need for Calibration and Adaptation }\end{array}$ & $\begin{array}{l}\text { Games for physical therapy, Mapping of sensor data } \\
\text { to game events }\end{array}$ & - & Playing \\
\hline Mazalek et al. [80] & 2011 & $\begin{array}{l}\text { I'm in the Game: Embodied Puppet Interface } \\
\text { Improves Avatar Control }\end{array}$ & $\begin{array}{l}\text { Puppet, tangible user interface, embodied inter- } \\
\text { aface, virtual character, video game, common cod- } \\
\text { ing, body memory, creativity }\end{array}$ & - & Playing \\
\hline $\begin{array}{l}\text { Mickelson and } \mathrm{Ju} \\
{[84]}\end{array}$ & 2011 & $\begin{array}{l}\text { Math Propulsion: Engaging Math Learners } \\
\text { Through Embodied Performance \& Visualiza- } \\
\text { tion }\end{array}$ & $\begin{array}{l}\text { Embodied, cognition, visualization, mathematics, } \\
\text { education }\end{array}$ & - & $M \& A$ \\
\hline Harrison et al. [43] & 2012 & On-Body Interaction: Armed and Dangerous & $\begin{array}{l}\text { Computer vision, projectors, depth camera, vision- } \\
\text { based input, free-space gestures, sensing, Arumura }\end{array}$ & - & $\mathrm{F} \& \mathrm{R}$ \\
\hline Feitsch et al. [30] & 2014 & $\begin{array}{l}\text { Tangible and Body-Related Interaction Tech- } \\
\text { niques for a Singing Voice Synthesis Installa- } \\
\text { tion }\end{array}$ & $\begin{array}{l}\text { tangible musical interfaces, 3D character perfor- } \\
\text { mance, singing voice synthesis, interactive media } \\
\text { installation }\end{array}$ & - & $M \& A$ \\
\hline Feltham et al. [31] & 2014 & $\begin{array}{l}\text { The Slow Floor: Increasing creative agency } \\
\text { while walking on an interactive surface }\end{array}$ & $\begin{array}{l}\text { Design prototyping, embodied interaction, interac- } \\
\text { tive surfaces, movement and perception, user eval- } \\
\text { uation. }\end{array}$ & theory & $F \& R$ \\
\hline Mueller et al. [89] & 2014 & Designing Mediated Combat Play & $\begin{array}{l}\text { Exertion game; exertion interface; whole-body in- } \\
\text { teraction; exergame; sport; combat; distributed in- } \\
\text { teraction }\end{array}$ & - & Playing \\
\hline $\begin{array}{ll}\text { Pijnappel and } & \\
\text { Mueller [103] } & \end{array}$ & 2014 & $\begin{array}{l}\text { Designing Interactive Technology for Skate- } \\
\text { boarding }\end{array}$ & $\begin{array}{l}\text { Skateboarding; exertion games; trick-focused } \\
\text { sports }\end{array}$ & design & Playing \\
\hline Walmink et al. [128] & 2014 & $\begin{array}{l}\text { Displaying Heart Rate Data on a Bicycle Hel- } \\
\text { met to Support Social Exertion Experiences }\end{array}$ & $\begin{array}{l}\text { Heart rate; biofeedback; body-worn technologies; } \\
\text { wearables; exertion; cycling; helmet. }\end{array}$ & - & $\mathrm{F} \& \mathrm{R}$ \\
\hline Chu et al. [19] & 2015 & $\begin{array}{l}\text { Augmenting Children's Creative Self-Efficacy } \\
\text { and Performance through Enactment-Based } \\
\text { Animated Storytelling }\end{array}$ & $\begin{array}{l}\text { Creativity; Storytelling; Enactment; Embodied In- } \\
\text { teraction }\end{array}$ & - & Playing \\
\hline Gervais et al. [35] & 2016 & TOBE: Tangible Out-of-Body Experience & $\begin{array}{l}\text { Physiological Computing; Tangible Interaction; } \\
\text { Spatial Augmented Reality; EEG; ECG; EDA }\end{array}$ & - & $\mathrm{F} \& \mathrm{R}$ \\
\hline Spiel et al. [120] & 2016 & $\begin{array}{l}\text { Embodied Companion Technologies for Autis- } \\
\text { tic Children }\end{array}$ & $\begin{array}{l}\text { Embodiment; Case Studies; Prototypes; Autism; } \\
\text { Children; Co-Design }\end{array}$ & - & $F \& R$ \\
\hline
\end{tabular}

Table 10: Papers making a technology contribution within the corpus. $C 2$ refers to the secondary contribution made, if applicable. SC refers to the subcontribution made. M\&A denotes a contribution in the area of 'Making Music \& Art', F\&R indicates a contribution connected to 'Feeling \& Reflecting'. (1/2) 


\begin{tabular}{|c|c|c|c|c|c|}
\hline Paper & Year & Title & keywords & $\mathrm{C} 2$ & SC \\
\hline $\begin{array}{l}\text { Núñez Pacheco and } \\
\text { Loke [99] }\end{array}$ & 2017 & $\begin{array}{l}\text { Tacit Narratives: Surfacing Aesthetic Meaning } \\
\text { by Using Wearable Props and Focusing }\end{array}$ & $\begin{array}{l}\text { HCI; wearables; aesthetics of interaction; somaes- } \\
\text { thetics; Focusing; experience; meaning }\end{array}$ & theory & Wearing \\
\hline Pon et al. [104] & 2017 & $\begin{array}{l}\text { Torrent: Integrating Embodiment, Physicaliza- } \\
\text { tion and Musification in Music-Making }\end{array}$ & $\begin{array}{l}\text { Electroacoustic Music; Embodied Interaction; Phys- } \\
\text { icalization; Musification; Electromyography }\end{array}$ & design & $M \& A$ \\
\hline Harley et al. [42] & 2018 & $\begin{array}{l}\text { Sensory VR: Smelling, Touching, and Eating } \\
\text { Virtual Reality }\end{array}$ & $\begin{array}{l}\text { Tangible and embodied interaction; virtual reality; } \\
\text { interactive narratives; diegetic design; sensory de- } \\
\text { sign; non-digital }\end{array}$ & - & $\mathrm{F} \& \mathrm{R}$ \\
\hline $\begin{array}{l}\text { Kleinberger } \\
\text { Panjwani [64] }\end{array}$ & 2018 & $\begin{array}{l}\text { Digitally Enchanted Wear: a Novel Approach } \\
\text { in the Field of Dresses as Dynamic Digital } \\
\text { Displays }\end{array}$ & $\begin{array}{l}\text { Wearables, projection, wearable computing, aug- } \\
\text { mented fashion }\end{array}$ & - & Wearing \\
\hline $\begin{array}{ll}\text { Tsaknaki } & \text { and } \\
\text { Elblaus [122] } & \end{array}$ & 2019 & $\begin{array}{l}\text { A Wearable Nebula - Material Investigations } \\
\text { of Implicit Interaction }\end{array}$ & $\begin{array}{l}\text { Implicit Interaction; Wearable technology; Craft- } \\
\text { ing; Sound and Music Computing; Materials }\end{array}$ & design & Wearing \\
\hline Flechtner et al. [32] & 2020 & $\begin{array}{l}\text { Designing a Wearable Soft-Robotic Orthosis: } \\
\text { A Body-Centred Approach }\end{array}$ & $\begin{array}{l}\text { Soft Robotics; Body-Centered Design; Bodystorm- } \\
\text { ing; Participatory Design; Orthotics; Human Ma- } \\
\text { chine interaction }\end{array}$ & design & Wearing \\
\hline $\begin{array}{l}\text { Ingebritsen et al. } \\
{[54]}\end{array}$ & 2020 & $\begin{array}{l}\text { Social Movements: A Case Study in } \\
\text { Dramaturgically-Driven Sound Design } \\
\text { for Contemporary Dance Performance to } \\
\text { Mediate Human-Human Interaction }\end{array}$ & $\begin{array}{l}\text { digital musical instruments; kinesthetic empathy; } \\
\text { sonification; contemporary dance; audience partic- } \\
\text { ipation }\end{array}$ & design & $M \& A$ \\
\hline Mueller et al. [91] & 2020 & $\begin{array}{l}\text { "Erfahrung \& Erlebnis": Understanding the } \\
\text { Bodily Play Experience through German Lexi- } \\
\text { con }\end{array}$ & $\begin{array}{l}\text { Whole-body interaction; bodily play; exertion } \\
\text { games; play; games }\end{array}$ & theory & Playing \\
\hline Mueller et al. [90] & 2020 & Towards Designing Bodily Integrated Play & $\begin{array}{l}\text { Bodily integration; play; cyborg; transhuman; } \\
\text { whole-body interaction }\end{array}$ & theory & Playing \\
\hline Mueller et al. [92] & 2020 & Towards Experiencing Eating as Play & $\begin{array}{l}\text { Food; Eating; Human-Food Interaction; FoodCHI; } \\
\text { Play }\end{array}$ & design & Playing \\
\hline Novak [98] & 2020 & Awareables: Beyond Wearable Technology & $\begin{array}{l}\text { Design engineering; four-dimensional (4D) prod- } \\
\text { uct; human-centered design; human-computer in- } \\
\text { teraction; product design; ubiquitous computing; } \\
\text { wearable computing }\end{array}$ & theory & Wearing \\
\hline $\begin{array}{l}\text { Turmo Vidal et al. } \\
\text { [124] }\end{array}$ & 2020 & $\begin{array}{l}\text { Training Body Awareness and Control with } \\
\text { Technology Probes: A Portfolio of Co-Creative } \\
\text { Uses to Support Children with Motor Chal- } \\
\text { lenges }\end{array}$ & $\begin{array}{l}\text { Physical Training; Technology Probes; Co- } \\
\text { Creation; Children; Somatic Exploration; Circus; } \\
\text { Body Awareness }\end{array}$ & design & $\mathrm{F} \& \mathrm{R}$ \\
\hline
\end{tabular}

Table 11: Papers making a technology contribution within the corpus. C2 refers to the secondary contribution made, if applicable. SC refers to the subcontribution made. M\&A denotes a contribution in the area of 'Making Music $\&$ Art', F\&R indicates a contribution connected to 'Feeling \& Reflecting'. (2/2) 


\begin{tabular}{|c|c|c|c|c|c|}
\hline Paper & Year & Title & keywords & $\mathrm{C} 2$ & SC \\
\hline Moen [86] & 2007 & $\begin{array}{l}\text { From Hand-Held to Body Worn: Embodied Ex- } \\
\text { periences of Design and Use of a Wearable } \\
\text { Movement-Based Interaction Concept }\end{array}$ & $\begin{array}{l}\text { Movement quality, movement-based interaction, } \\
\text { kinesthetics, wearable artifacts, embodied inter- } \\
\text { action, social context of use }\end{array}$ & design & $A \& D$ \\
\hline Larssen et al. [66] & 2007 & $\begin{array}{l}\text { The Feel Dimension of Technology Interaction: } \\
\text { Exploring Tangibles through Movement and } \\
\text { Touch }\end{array}$ & $\begin{array}{l}\text { Body, Embodiment, Interaction, Interaction de- } \\
\text { sign, Kinesthetic sense, Movement, Phenomenol- } \\
\text { ogy, Tangibility, Touch }\end{array}$ & - & $\mathrm{P}$ \\
\hline Feltham et al. [31] & 2014 & $\begin{array}{l}\text { The Slow Floor: Increasing creative agency } \\
\text { while walking on an interactive surface }\end{array}$ & $\begin{array}{l}\text { Design prototyping, embodied interaction, inter- } \\
\text { active surfaces, movement and perception, user } \\
\text { evaluation. }\end{array}$ & technology & $A \& D$ \\
\hline $\begin{array}{l}\text { Nam and Nitsche } \\
\text { [93] }\end{array}$ & 2014 & $\begin{array}{l}\text { Interactive Installations as Performance: Inspi- } \\
\text { ration for HCI }\end{array}$ & $\begin{array}{l}\text { Interactive installations; human-computer inter- } \\
\text { action; digital art; performance; physical inter- } \\
\text { afaces; bodily movements. }\end{array}$ & - & $\mathrm{P}$ \\
\hline $\begin{array}{l}\text { van Dijk et al. } \\
{[126]}\end{array}$ & 2014 & $\begin{array}{l}\text { Beyond Distributed Representation: Em- } \\
\text { bodied Cognition Design Supporting Socio- } \\
\text { Sensorimotor Couplings }\end{array}$ & $\begin{array}{l}\text { Embodied Cognition, situatedness, practice, sen- } \\
\text { sorimotor coupling, interaction, design, theory, } \\
\text { tangible, augmented }\end{array}$ & - & $\mathrm{P}$ \\
\hline $\begin{array}{l}\text { Hummels and van } \\
\text { Dijk [53] }\end{array}$ & 2015 & $\begin{array}{l}\text { Seven Principles to Design for Embodied Sense- } \\
\text { making }\end{array}$ & $\begin{array}{l}\text { Sensemaking; embodiment; social coordination; } \\
\text { tangible interaction; communication; design pro- } \\
\text { cess }\end{array}$ & design & $\mathrm{P}$ \\
\hline $\begin{array}{l}\text { Núñez Pacheco } \\
\text { and Loke [99] }\end{array}$ & 2017 & $\begin{array}{l}\text { Tacit Narratives: Surfacing Aesthetic Meaning } \\
\text { by Using Wearable Props and Focusing }\end{array}$ & $\begin{array}{l}\mathrm{HCI} \text {; wearables; aesthetics of interaction; somaes- } \\
\text { thetics; Focusing; experience; meaning }\end{array}$ & technology & $\mathrm{P}$ \\
\hline $\begin{array}{l}\text { van Dijk and Hum- } \\
\text { mels [125] }\end{array}$ & 2017 & $\begin{array}{l}\text { Designing for Embodied Being-in-the-World: } \\
\text { Two Cases, Seven Principles and One Frame- } \\
\text { work }\end{array}$ & $\begin{array}{l}\text { Embodied Being-in-the-World; assistive technol- } \\
\text { ogy; empowerment; tangible interaction; ubiqui- } \\
\text { tous computing }\end{array}$ & design & $\mathrm{P}$ \\
\hline Mueller et al. [91] & 2020 & $\begin{array}{l}\text { "Erfahrung \& Erlebnis": Understanding the Bod- } \\
\text { ily Play Experience through German Lexicon }\end{array}$ & $\begin{array}{l}\text { Whole-body interaction; bodily play; exertion } \\
\text { games; play; games }\end{array}$ & technology & $\mathrm{P}$ \\
\hline Mueller et al. [90] & 2020 & Towards Designing Bodily Integrated Play & $\begin{array}{l}\text { Bodily integration; play; cyborg; transhuman; } \\
\text { whole-body interaction }\end{array}$ & theory & N/A \\
\hline Novak [98] & 2020 & Awareables: Beyond Wearable Technology & $\begin{array}{l}\text { Design engineering; four-dimensional (4D) prod- } \\
\text { uct; human-centered design; human-computer } \\
\text { interaction; product design; ubiquitous comput- } \\
\text { ing; wearable computing }\end{array}$ & technology & N/A \\
\hline
\end{tabular}

Table 12: Papers making a theoretical contribution within the corpus. $\mathrm{C} 2$ refers to the secondary contribution made, if applicable. SC refers to the subcontribution made. N/A indicates that none was specified, A\&D refers to 'Aesthetics \& Dance' and $P$ denotes Phenomenology. 